\title{
Adrenergic Tone as an Intermediary in the Temperament Syndrome Associated With Flight Speed in Beef Cattle
}

OPEN ACCESS

Edited by:

Neil Price Evans,

University of Glasgow,

United Kingdom

Reviewed by:

Maud Bonato,

Stellenbosch University, South Africa

Aline Cristina Sant'Anna,

Juiz de Fora Federal University, Brazil

${ }^{*}$ Correspondence:

lan G. Colditz

ian.colditz@csiro.au

Specialty section:

This article was submitted to Animal Physiology and Management,

a section of the journal

Frontiers in Animal Science

Received: 12 January 2021 Accepted: 10 February 2021

Published: 10 March 2021

Citation: Colditz IG (2021) Adrenergic Tone as an Intermediary in the Temperament

Syndrome Associated With Flight Speed in Beef Cattle.

Front. Anim. Sci. 2:652306. doi: 10.3389/fanim.2021.652306

\author{
Ian G. Colditz* \\ CSIRO Agriculture and Food, Armidale, NSW, Australia
}

The temperament of farm animals can influence their resilience to everyday variations within the managed production environment and has been under strong direct and indirect selection during the course of domestication. A prominent objective measure used for assessing temperament in beef cattle is the behavioral flight response to release from confinement in a crush or chute. This behavioral measure, termed flight speed (also known as escape velocity) is associated with physiological processes including body temperature, feeding behavior, growth rate, carcass composition, immune function, and health outcomes. This review examines the functional links between this suite of traits and adrenergic activity of the sympathetic nervous system and the adrenomedullary hormonal system. It is suggested that flight speed is the behavioral aspect of an underlying "flightiness" temperament syndrome, and that elevated adrenergic tone in animals with a high level of flightiness (i.e., flighty animals) tunes physiological activities toward a sustained "fight or flight" defense profile that reduces productivity and the capacity to flourish within the production environment. Nonetheless, despite a common influence of adrenergic tone on this suite of traits, variation in each trait is also influenced by other regulatory pathways and by the capacity of tissues to respond to a range of modulators in addition to adrenergic stimuli. It is suggested that tuning by adrenergic tone is an example of homeorhetic regulation that can help account for the persistent expression of behavioral and somatic traits associated with the flight speed temperament syndrome across the life of the animal. At a population level, temperament may modulate ecological fit within and across generations in the face of environmental variability and change. Associations of flight speed with the psychological affective state of the animal, and implications for welfare are also considered. The review will help advance understanding of the developmental biology and physiological regulation of temperament syndromes.

Keywords: temperament, flight speed, immune competence, body temperature, epinephrine, norepinephrine, dopamine, metabolism

\section{INTRODUCTION}

Animals engage with their environment through behavioral activities in order to harvest resources, seek rewards and avoid threats. Individual differences in perception of the environment and in the behavioral responses to those perceptions lead to the expression of a range of behavioral types within a population (Sih et al., 2004; Réale et al., 2007; Dingemanse et al., 2010). In ecological 
studies, the coupling of behaviors to physiological and immune processes is thought to influence life history and environmental fitness (Biro and Stamps, 2008, 2010; Careau et al., 2008; Koolhaas, 2008; Koolhaas et al., 2010; Capitanio and Mason, 2019). Persistent patterns of behavioral activity that are repeated in different environmental contexts or repeated across time within a single context are considered to reflect an aspect of the individual's temperament or personality (Lyons et al., 1988; Réale et al., 2007; Koolhaas et al., 2010; MacKay and Haskell, 2015; Finkemeier et al., 2018). For humans and farm animals, these ecological interactions between temperament traits and stress and immune response pathways (Benus et al., 1991; Koolhaas et al., 1999; Koolhaas, 2008; Burdick et al., 2011b; Capitanio, 2011; Hine et al., 2019) gain clinical importance through their influence on disease susceptibility, welfare, and livestock production (Segerstrom, 2003; Haskell et al., 2014; Koolhaas and van Reenen, 2016).

When an animal perceives a challenge within the ebb and flow of daily events, response pathways are activated that defend its integrity. Activation of the hypothalamic pituitary adrenal system (HPA) leads to release of cortisol from the adrenal cortex, while increased activity of the sympathetic nervous system (SNS) leads to rapid release of norepinephrine at nerve endings within most organs and tissues of the body. The SNS also innervates the adrenal medulla and stimulates the adrenomedullary hormone system (AHS) to release epinephrine and small amounts of norepinephrine (Holzbauer and Sharman, 1972; Goldstein, 2003). Epinephrine and norepinephrine contribute to the fight or flight response. A family of six alpha and three beta adrenergic receptors that differ in tissue distribution and sensitivity to norepinephrine and epinephrine provide fine tuning of adrenergic responses at the tissue level (Badino et al., 2005) as seen for example in control of milk release form the bovine mammary gland (Blum et al., 1989). HPA, SNS, and AHS messengers are not only deployed when integrity is under threat but are also released tonically and contribute to the continuous regulation of homeostasis (Sundlöf and Wallin, 1977; Vicente et al., 2002; Goldstein, 2003). Variations in the level of HPA, SNS, and AHS activity provide a dynamic orchestration of the allocation of resources between defense and flourishing in accord with the felicity of environmental conditions the animal is experiencing (Rauw et al., 2017). Unresolved motivations to harvest resources, to acquire rewards or to avoid threats also lead to elevated HPA, AHS, and SNS activity (Jensen and Toates, 1997). As a consequence, measurement of HPA, AHS, and SNS activity plays a prominent role in studies of animal welfare (Mormède et al., 2007).

Among the changes in farm animals that have occurred during domestication, it is thought that the threshold for perception of threats has increased while the strength of physiological responses to stressors has decreased (Price, 1999; MignonGrasteau et al., 2005; Jensen, 2014; Wilkins, 2020). Nonetheless, there is substantial variation in temperament between individuals within a breed or species, and in the behavioral, physiological, and immune activities mobilized in the presence of perceived threats (Koolhaas et al., 1999, 2010; Boissy et al., 2005). In beef cattle, flight speed (FS) has attracted attention as a measure of temperament, and a large literature examines its associations with physiological functions, health, and production traits (for reviews see Burrow, 1997; Burdick et al., 2011b; Cooke, 2014; Haskell et al., 2014). The reader is referred to those reviews for detailed critiques of experimental studies on temperament (especially FS) and its association with physiology, health, production, and reproduction traits. This review focusses on the mechanistic associations between adrenergic activity, metabolism, immune function, and psychological affect that may contribute to the observed phenotypic associations of traits with FS seen in some studies. Section 2 provides a brief summary of biological functions and production traits associated with FS. In Section 3, experimental studies in cattle and other species on the influence of adrenergic activities on the biological functions underpinning production traits is examined. Section 4 examines the roles of homeorhesis and allostasis in regulating homeostatic states of the animal. Homeorhesis as a mechanism for the persistence of temperament, and the potential role of candidate genes identified in genomic studies in this mechanism are examined in Section 5. These concepts are drawn together in Section 6 to suggested that the behavioral response measured by FS is an acute expression of a persistent underlying temperament syndrome that balances behavior, metabolism, and immune functions along an axis between preparedness for defense and more generative flourishing. It is suggested that persistent variation between individual animals in adrenergic tone contributes to the temperament syndrome.

\section{FLIGHT SPEED}

\subsection{Measuring the Trait}

Pioneering work beginning in the 1960s established standardized methods for quantifying the behavioral activities of beef cattle during handling procedures (Tulloh, 1961; Hearnshaw et al., 1979; Fordyce et al., 1982). In accord with folk wisdom, differences in behavior observed between individuals were found to be repeatable and the scored behavior was found to vary between breeds of cattle, to be heritable and also to be influenced by experience (Tulloh, 1961; Hearnshaw et al., 1979; Fordyce et al., 1982). Initial methods used categorical subjective scores. Tulloh (1961) summarized behavior as cattle entering the scales, the crush, and the bail by allotting scores in a range from 1 (best) to 4 (worst). Hearnshaw et al. (1979) assessed responses to restraint in a head bail by the behaviors: tail swishing, straining back; backward and forward movement; paddling with the back feet in an attempt to escape; kicking: kneeling; jumping. These behaviors were used to generate a combined score described in words as $0=$ stands very quietly, offers no resistance, only casual tail swishing; 1 = generally quiet, offers token resistance, steady movement in bail head; 2 = involves slightly excited movement, straining and paddling, may kick; 3 = excited, vigorous abrupt movement, straining, paddling; may jump, or kneel; $4=$ very disturbed, frightened, wild movements etc, may jump and goes down in crush; $5=$ unmanageable and dangerous. Fordyce et al. (1982) assessed cattle in a crush test, a race test and a head bail test scoring movement on a scale from 1 to 7 and respiration on a scale of 1 to 4 . These authors also introduced 
two continuous quantitative measures by counting the number of quadrants a beast crossed in a $60 \mathrm{~s}$ interval when confined in a circular yard with a $6 \mathrm{~m}$ diameter with an observer at the center, and the closest distance measured in paces that a human could approach an animal in a 20 by $30 \mathrm{~m}$ yard. The complexity of these scoring systems highlights the importance of the method subsequently developed by Burrow et al. (1988). These authors used an objective measure by recording the time taken for an animal to traverse a distance of $1.7 \mathrm{~m}$ when released from confinement in a crush (chute) or weighing box. This measure generates a continuous variable for analysis of genetic parameters (Burrow, 1997). Flight time is commonly converted to FS $(\mathrm{m} / \mathrm{s})$ for analysis. FS (also known as escape velocity) is a quantitative trait that often displays a broad distribution within a study population (Figure 1). A number of subjective and objective methods for measuring behavioral activity of cattle during handling have subsequently been developed (reviewed by Haskell et al., 2014), however, amongst these tests, FS has been most widely used in studies of behavior, physiology, and genetics. A "temperament" score combining FS with a subjective measure such as chute score or pen score is also commonly used (e.g., Burdick et al., 2011c; Francisco et al., 2015; Lee et al., 2018), and a subjective score of behavior as the animal exits the crush is used in some studies (e.g., Schwartzkopf-Genswein et al., 2012). Many studies in beef cattle implicitly or explicitly adopt a model of temperament as a singular one-dimensional characteristic of the animal that can be described with terms such as calm and agitated, or good and poor temperament, or adequate and excitable (e.g., Fell et al., 1999; Cooke, 2014). Some studies, however, have examined temperament as a multidimensional attribute of the animal (for examples see van Reenen et al., 2002, 2004; Van Reenen et al., 2005; Kilgour et al., 2006; Petherick

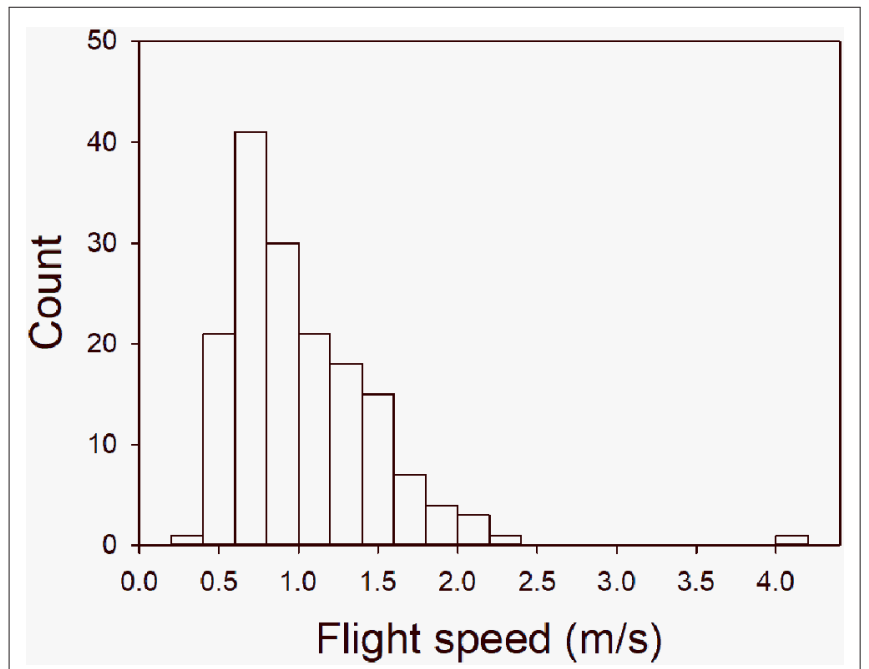

FIGURE 1 | Frequency histogram of the distribution of flight speed $(\mathrm{m} / \mathrm{s})$ in a cohort of 164 Angus steers measured on Day 1 of weaning. Calves were the progeny of 47 sires used in a sire genetic benchmarking program and were born and raised at pasture in a single contemporary management group. Adapted from Hine et al. (2019). et al., 2009b; Cafe et al., 2011a) which aligns more closely with the multi-dimensional construct of temperament used more broadly in the behavioral ecology and psychology literatures (Réale et al., 2007; Koolhaas et al., 2010; MacKay and Haskell, 2015; Finkemeier et al., 2018; Capitanio and Mason, 2019). The terms used to describe temperament in the following section (e.g., good, poor, temperamental, calm) reflect those of the authors cited below.

\subsection{Associations With Production Traits}

Beginning with the earliest quantitative studies, associations with physiological processes such as growth rate were recognized (e.g., Tulloh, 1961). Favorable phenotypic and genetic associations have been found between good temperament (usually assessed as low FS) and higher feed intake, higher growth rate, higher intramuscular fat percentage, higher intramuscular glycogen, higher pregnancy rate, and lower disease incidence during feedlot finishing (Voisinet et al., 1997a,b; Kadel et al., 2006; King et al., 2006; Müller and von Keyserlingk, 2006; Petherick et al., 2009a; Cafe et al., 2011a,b; McGilchrist et al., 2011; Sebastian et al., 2011; Sant'Anna et al., 2012; Cooke, 2014; Llonch et al., 2016; Bruno et al., 2018). Favorable associations have been seen in cattle run at pasture and during feedlot finishing (Ferguson et al., 2006; Cafe et al., 2011b). Contrary results for some measures have also been observed (e.g., Burrow and Dillon, 1997; Prayaga and Henshall, 2005; Bruno et al., 2018). For further references and discussion of associations with production traits see Haskell et al. (2014).

\subsection{Associations With Baseline Values of Physiological and Immune Variables}

The search for proximate mechanisms underlying the associations between activity during handling and measures of animal productivity has found elevated basal cortisol and epinephrine (Fell et al., 1999; Curley K. O. J. et al., 2006; King et al., 2006; Petherick et al., 2009a; Burdick et al., 2011a,c; Cafe et al., 2011a), higher basal glucose, lactate (Petherick et al., 2009a; Boles et al., 2015; Williams et al., 2019) and non-esterified fatty acid (NEFA) concentrations in blood (Cafe et al., 2011a; Burdick Sanchez et al., 2016), higher basal temperature (Burdick et al., 2011c; Williams et al., 2019; Lees et al., 2020; Parham et al., 2021), and higher heart rate (Parham et al., 2021) in cattle with poor temperament. Few leukocyte variables differ between cattle with poor or good temperament (Fell et al., 1999; Hulbert et al., 2011). Accurate estimates of baseline values are difficult to obtain without habituation of animals to handling and confinement, and subsequent collection of blood samples via indwelling catheters (Cafe et al., 2011a; Burdick Sanchez et al., 2016). In many studies and as acknowledged by the authors, the estimates of baseline values obtained from cattle mustered and handled through yards are likely to be influenced by HPA, SNS, and AHS responses to handling before blood samples are drawn (Petherick et al., 2009a; Williams et al., 2019). A number of studies have found that temperamental cattle have reduced feed intake (Black et al., 2013; Llonch et al., 2018), increased feeding bouts of shorter duration (Llonch et al., 2018) and reduced feeding times (Nkrumah et al., 2007; Cafe et al., 2011a). 


\subsection{Associations With Muscle Physiology and Carcass Characteristics}

Exercise increases anaerobic glycolysis in muscle (Holmes et al., 1972) and leads to an increase in blood lactate following its transport out of muscle cells (Williams et al., 2019). Blood (Holmes et al., 1972; Petherick et al., 2009a; Boles et al., 2015; Williams et al., 2019) and muscle lactate (McGilchrist et al., 2011) are elevated and muscle glycogen lower (McGilchrist et al., 2011) in temperamental cattle scored categorically (Holmes et al., 1972) or by FS (McGilchrist et al., 2011; Boles et al., 2015; Williams et al., 2019). In post-mortem carcass analyses, FS was associated with higher muscle lactate (McGilchrist et al., 2011; Coombes et al., 2014), lower fat cover (Cafe et al., 2011b), lower intramuscular fat (marbling) (Cafe et al., 2011b; Francisco et al., 2015), higher pH (Cafe et al., 2011b), and higher shear force (Voisinet et al., 1997a; Kadel et al., 2006; King et al., 2006; Behrends et al., 2009; Cafe et al., 2011b; Boles et al., 2015). An effect of FS on $\mathrm{pH}$ and muscle glycogen was not seen in all studies (Coombes et al., 2014). Differences between calm and temperamental cattle in muscle mitochondrial function have also been observed (Owen et al., 2020).

\subsection{Associations With Changes in Physiological, Immune, and Behavioral Variables Following Experimental Challenges}

The influence of reactivity to handling on responses to environmental challenges that are typically encountered in the production environment has been explored in a number of studies described below. In response to transport for $9 \mathrm{~h}$, rectal temperature increased in temperamental and calm 10 month old bull calves with a peak at $30 \mathrm{~min}$. Temperamental bulls had a higher rectal temperature throughout the study and a temperament group by time interaction was not reported (Burdick et al., 2011a). The higher concentrations of cortisol and epinephrine in temperamental bulls observed before transport were also evident after transport with little observed change from the pretransport values. In calm bulls, cortisol increased during transport whereas there was little change from initial high levels in epinephrine concentrations. At feedlot entry and 5 days later, a suite of hematological variables did not differ between temperament groups of Bos taurus steers (Fell et al., 1999). Nonetheless, health outcomes differed between groups with a higher percentage of temperamental steers being removed to the hospital pen. Reinhardt et al. (2009) reported that mortality during feedlot finishing increased with subjectively scored behavior on exit from the chute, although the number of treatments for respiratory disease was not associated with temperament score. In contrast to health outcomes in feedlot cattle, there is little evidence of genetic or phenotypic effects of FS on tick, buffalo fly or worm burdens in topical adapted beef cattle grazing at pasture (Burrow, 2001; Prayaga, 2003; Prayaga and Henshall, 2005).

Several studies have examined the influence of temperament on immune system activity. The antibody response to vaccination at weaning with a commercial leptospirosis vaccine was compared in eight steers with low FS and eight steers with high FS. Antibody titers to Leptospira were significantly higher in the low FS group (Bruno et al., 2018). In 1149 Angus calves receiving clostridial vaccination during the stress of yard weaning, IgG antibody responses to tetanus toxoid, and delayed type hypersensitivity responses to intradermal injection of clostridial antigens were not phenotypically correlated with FS, however favorable genetic correlations were seen for both immune function traits (Hine et al., 2019). Thus, docile temperament was genetically correlated with elevated adaptive immune responses. In a contrast between 10 temperamental and 10 calm bull calves vaccinated with a clostridial vaccine at weaning and boosted 4 weeks later, there was a tendency for IgG antibody titres to be higher at the end of the primary antibody response period in calm calves, although the treatment by time interaction was not significant (Oliphint, 2006). Lymphocyte proliferation in vitro following mitogen stimulation was higher in calm calves. In responses to injection of bacterial lipopolysaccharide (LPS, endotoxin), which primarily activates the innate immune system, expression of sickness behaviors and fever were blunted in temperamental weaned bull calves (Burdick et al., 2011c). Cortisol response to the LPS challenge was not affected by temperament whereas epinephrine responses were elevated in temperamental calves.

Following epinephrine injection, temperamental cattle had a greater increase in blood lactate concentration than quiet cattle (Holmes et al., 1972). Following glucose and insulin challenges, temperamental calves had a lower insulin response, were slower to clear glucose from blood and exhibited relative insulin insensitivity (Burdick Sanchez et al., 2016). Studies of the cortisol response to ACTH challenge have found no association between FS and peak cortisol concentrations (Curley et al., 2008; Cafe et al., 2011a). The results suggest that the elevated baseline HPA activity in temperamental cattle is not associated with a chronic stress status and attenuated adrenal reactivity.

The influence of FS on behavioral responses in a threat perception test has been examined in 8 month old Angus steers (Lee et al., 2018). The test measures a suite of behaviors following exposure to a dog. There was a significant association between poor temperament based on temperament index (combining FS and chute score) and increased number of zones crossed in the test arena, increased attention toward the threat and tail swishing, and there was a tendency for vigilance to be increased in temperamental cattle (Lee et al., 2018). Elevated activity of these behaviors has been interpreted previously as signs the animal is in a negatively valenced state with increased arousal, i.e., a negative psychological affective state as discussed further below (Lee et al., 2016; Monk et al., 2018). Interestingly, FS was not modified by treatment with the anxiogenic drug 1methy-chlorophenylpiperazine. The results support a tentative conclusion that flighty cattle have a more negative affect state than calm cattle when exposed to an aversive environmental challenge (Lee et al., 2018). 


\section{INFLUENCE OF ADRENERGIC PATHWAYS ON TRAITS ASSOCIATED WITH FS}

A prominent feature of these studies is the association with heightened adrenergic activity in temperamental cattle (Burdick et al., 2011c; Cafe et al., 2011a). In contrast, despite higher baseline levels of cortisol in temperamental cattle, HPA responsiveness to environmental challenges is comparable in calm and temperamental cattle in most studies (Curley et al., 2008; Cafe et al., 2011a) (Supplementary Material). This section examines the influence of SNS and AHS activity on physiological and immune responses and affective state. Adrenergic effects are mediated primarily by the catecholamines norepinephrine in the SNS and epinephrine in the AHS (Burdick et al., 2011b). The third catecholamine, dopamine, is also active in peripheral tissues, especially kidney, gut, and immune cells (Falck et al., 1964; Matt and Gaskill, 2019; Broome et al., 2020). Activity of the SNS and AHS pathways can differ both at rest and in response to specific types of stressor (Goldstein, 2003). SNS and AHS actions are broadly conserved across mammalian species, although some species differences occur, for instance in sensitivity to adrenergic agonists and relative concentrations of norepinephrine and epinephrine at rest and in responses to environmental challenges (Dunshea and D'Souza, 2003). Where data are not available for cattle, the general model of adrenergic influence on physiological and immune functions is described. Discussion focuses on studies in cattle which have employed infusion of epinephrine or norepinephrine to examine short term effects of adrenergic activation on physiological mechanisms, and injection of synthetic adrenergic agonists and antagonists such as clenbuterol and propranolol on longer term effects of adrenergic activation or inhibition. For reviews of adrenergic influences on reproduction in beef cattle see (Fernandez-Novo et al., 2020) and on appetite see (Wellman, 2005). For comments on limitations associated with the scope of the review see Supplementary Material.

\subsection{Core Body Temperature and Metabolism}

Studies summarized in Section 2.3 indicate that FS is associated with variation in body temperature and metabolism. Body temperature is regulated by balancing heat generation and heat loss (Gale, 1973). Obligatory heat produced from metabolic activity, motor activity and digestion-related thermogenesis can be augmented to defend core body temperature during cold exposure via involuntary muscular shivering and nonshivering thermogenesis in brown adipose tissue (Hohtola, 2004). Norepinephrine infusion in new-born calves induces heat production in brown adipose tissue (Alexander et al., 1975; Thompson and Bell, 1976). The thermogenic response decreases over the first few days of the calf's life and is replaced by an increase in the lipolytic effect of epinephrine on white adipose tissue. Brown adipose tissue has not been found in adult cattle by histological examination (Bruce, 1998); however recent molecular studies suggest white adipose tissue can transition toward a "beige" or "brite" (BRown-In-whiTE) phenotype in adult cattle following cold exposure (and following exercise in a number of other species), with an associated restoration of thermogenic capacity via activity of uncoupling protein1 (Komolka et al., 2017). Catecholamines also contribute to thermogenesis by mobilizing energy reserves. Catecholamineinduced lipolysis leads to rapid release of NEFA that can be rapidly oxidized as an energy source. The NEFA response to epinephrine infusion is accompanied by elevated glucose concentrations in blood and reduced sensitivity to insulin (Pethick et al., 2005). These thermogenic effects are illustrated in cattle by the analgesic agent xylazine through its action as an $\alpha 2$-adrenergic agonist which induces increased blood glucose and decreased blood insulin concentrations together with increased body temperature and disrupted heat dissipation (Greene and Thurmon, 1988). In accord with these effects, the treatment of calves with the beta adrenergic agonist clenbuterol reduces energy retention and increases heat production (Williams et al., 1987). In contrast to the thermogenic effects of beta agonists, inhibition of sympathetic outflow by alpha agonists reduces basal metabolic rate, heat production and heart rate in cattle (Gazzola et al., 1995). Inactivation of norepinephrine by antibodies generated by immunizing cattle with norepinephrine had a similar effect (Gazzola and Hunter, 1999). The authors noted that the individual animal was a significant source of variation in statistical analyses of metabolic rate and heart rate, and to a lesser extent heart rate (Gazzola et al., 1995). This simple observation illustrates that individual animals differ in metabolic activity even when housed in the highly controlled environment of respiration chambers (Supplementary Material). As antibodies do not cross the blood brain barrier, additional studies were undertaken to examine the effect of intracerebral injection of alpha agonists on metabolic rate, heat production and heart rate (Hunter et al., 1993). Results confirmed that the target for activity on metabolic activity of the alpha agonists and antibodies to norepinephrine was in peripheral tissues (Hunter et al., 1993). Anticipation of feeding in steers induces sufficient adrenergic outflow to elevate NEFA (Boisclair et al., 1997). Tissue responses to catecholamines are influenced by the physiological state of the animal (Pethick et al., 2005) and by treatment with bovine somatotropin (Boisclair et al., 1997). In addition to effects on heat production, epinephrine infusion induces cutaneous vasoconstriction that reduces skin temperature and heat loss (Gale, 1973; Stewart et al., 2010). The influence of sympathetic activity on tone of peripheral vasculature has been used clinically in cattle to assess welfare stress status (Stewart et al., 2007).

Within a few minutes of exposure to a stressor there is a transient increase in core temperature termed stress-induced hyperthermia (SIH) (Bouwknecht et al., 2007). The response occurs independent of physical activity associated with stress and can be modulated with anxiogenic and anxiolytic drugs (Nakamura, 2011). This drug sensitivity leads SIH to be described as a response to psychological or emotional stress. The temperature increase involves sympathetic outflow and can be reduced in rats by beta antagonists (Nakamura, 2011). An SIH-like increase in temperature during handling in yards is seen in beef cattle (Lees et al., 2020). In accord with studies 
in rodents and sheep (Bouwknecht et al., 2007; Monk et al., 2018), SIH during a threat perception test in Angus steers was enhanced by pre-treatment with the anxiogenic drug 1methy-chlorophenylpiperazine; however, the anxiogenic drug treatment did not influence FS as noted above (Lee et al., 2018). Thus, adrenergic activity modulates metabolic rate and body temperature at rest, and modulates dynamic changes in these metabolic variables during physical and psychological challenges.

\subsection{Carcass Composition}

Studies summarized in Section 2.4 indicate that accumulation of fat within the body, and energy metabolism in muscle vary with FS. Studies on effects of adrenergic activity on muscle function, intramuscular fat metabolism and carcass composition in cattle have focused mainly on the effects of stressors, exercise and beta agonists. Adrenergic activity in these contexts increases insulin resistance, glycogen mobilization, lipolysis, cellular, and plasma lactate concentrations, and ultimate $\mathrm{pH}$ of meat following slaughter, and reduces intramuscular fat deposition (Pethick et al., 1995, 2005; Hocquette et al., 1998; Johnson et al., 2014). Beta agonists used as growth promotants induce hypertrophy of glycolytic type II muscle fibers and reduce intramuscular fat (Johnson et al., 2014).

In resting humans, sympathetic nerves innervating skeletal muscle exhibit short bursts of activity in synchrony with heart rate (Sundlöf and Wallin, 1977). Up to 10 -fold variation occurs between individual humans in the incidence of sympathetic impulses, yet within an individual, the pattern of impulses is consistent between different muscle groups, and consistent across time when measurements are repeated at intervals of up to 21 months. Norepinephrine released from this sympathetic outflow increases non-shivering thermogenesis (Mejsnar and Pácha, 1983) and spills over into draining blood thereby contributing to circulating levels of the neurotransmitter (Wallin et al., 1981). Indeed, persistent differences between individuals in plasma norepinephrine during rest are positively correlated with muscle sympathetic activity across time periods examined up to 45 months apart (Wallin et al., 1981). The impulses arise from central sympathetic drive and generate muscle sympathetic tone that differs between individuals (Sundlöf and Wallin, 1977). Changes in sympathetic tone modulate many physiological activities. For example, variations in sympathetic tone control the frequency of pulsatile contractions of the bovine teat sphincter muscles, and a reduction of sympathetic tone following stimulation of the udder leads to relaxation of the teat sphincter muscles which promotes removal of milk from the gland (Lefcourt, 1982; Blum et al., 1989). Together these observations in humans and cows suggest that variation between individuals in basal and dynamic adrenergic activities could contribute to the associations seen between flightiness, muscle physiology, and carcass composition in cattle. Studies on individual variation between cattle in activity of the sympathetic innervation of skeletal muscle seem warranted.

\subsection{Immune Function}

Studies have found associations between FS and activity of the innate and adaptive immune systems (Sections 2.3 and 2.5).
Adrenergic activity exerts an influence over immune functions via sympathetic innervation of primary and secondary lymphoid organs, and through activation of adrenergic receptors on leukocytes, especially cells of the monocyte-macrophage lineage (LaBranche et al., 2010; Irwin and Cole, 2011; Kenney and Ganta, 2011; Wohleb, 2019). In sheep, the beta agonist clenbuterol suppresses antibody responses to vaccination (Spencer and Oliver, 1996). Conversely, in mouse studies it was found that the beta antagonist propranolol enhances antibody responses and $\mathrm{T}$ helper 1 immune responses (Mazloomi et al., 2012). Studies of chronic social stressors in humans, rodents, and rhesus monkeys have identified a shift in gene expression in monocyte lineage leukocytes away from a pattern associated with strong antiviral and antibody defense toward a pattern associated with inflammatory defense (reviewed by Wohleb, 2019). This gene expression profile, termed a conserved transcriptional response to adversity, is marked by elevated expression of the cytokines IL-1 $\beta$, TNF $\alpha$, and IL- 6 and reduced expression of IFN $\gamma$ amongst other changes, and is associated with increased susceptibility to a range of inflammatory and infectious diseases (Cole, 2014, 2019; Cole et al., 2015; Fredrickson et al., 2015). In the species in which the pattern has been studied, it is primarily associated with norepinephrine release from SNS innervation of lymphoid organs (Sloan et al., 2008; Cole, 2019). It has been suggested that epigenetic changes in leukocytes induced by the elevated SNS activity, but not the HPA axis in these stress paradigms induces a persistent shift of immune functions toward inflammation and tissue repair in preparedness for fight or flight defenses (Irwin and Cole, 2011). As well as peripheral effects on immune function, catecholamines released in human and rodent models of stress act centrally to induce interleukin- $1 \beta$ within brain tissue and induce mood changes (Johnson et al., 2005; Wohleb, 2019).

A further mode of action of catecholamines on immune function is via the metabolic changes noted in Section 3.1. The innate immune system initiates inflammatory responses when sensory pathways that detect molecular patterns associated with pathogens and damaged host tissues are activated via a classical receptor-ligand pathway. Activation of the receptors (PAMPs and DAMPs) leads to assembly of intracellular multimolecular complexes termed inflammasomes which in turn leads to cleavage, maturation and release of the proinflammatory cytokines IL-1 $\beta$ and IL-18 (Liston and Masters, 2017). In addition to activation via these receptor-ligand sensory pathways, inflammasome assembly is also initiated through physicochemical and allosteric effects of elevated intracellular concentrations of a number of metabolites including NEFA and by products of cellular stress including reactive oxygen species and Heat Shock Protein 72 (Lacetera, 2016; Liston and Masters, 2017; Bronzo et al., 2020). Through this nonclassical activation pathway, metabolic changes such as elevated NEFA associated with elevated sympathetic tone can bias innate immune function toward inflammation and away from support of adaptive immune responses. Studies in cattle show that elevated NEFA concentration in plasma suppresses adaptive immune functions including proliferation of lymphocytes, and production of IgM and interferon $\gamma$ (Lacetera et al., 2004). 
The studies in humans and animal models by Cole and colleagues (Cole, 2014, 2019; Cole et al., 2015; Fredrickson et al., 2015) have examined the influence of a range of chronic environmental stressors experienced during childhood or adult life on immune function. In contrast to this influence of experience on immune function, a long standing research focus in humans (Segerstrom, 2003), laboratory (Benus et al., 1991), and farm animals (Koolhaas, 2008) has been the influence of heritable personality and temperament traits on immune function and disease susceptibility. Studies in humans, pigs, rodents, and some other species show that during social conflict, individuals can exhibit a proactive coping style associated with aggression, or a reactive style associated with withdrawal, immobility and low levels of aggression (Henry and Stephens, 1977; Koolhaas et al., 1999; Castanheira et al., 2017). Coping styles have been extensively studied in pigs using a "back test" to assess the behavioral response to restraint in a supine position for 60s (Hessing et al., 1994). When scored on a continuous scale, pigs exhibit a continuous unimodal distribution of responses between proactive and reactive styles (Forkman et al., 1995; Zebunke et al., 2015) that is similar to the unimodal distribution of FS in cattle (Figure 1). Pigs with a proactive coping style have low basal HPA activity, low HPA reactivity to stress, and high sympathetic and low parasympathetic reactivity. In contrast, pigs with a reactive coping style have normal basal HPA axis activity that increases under stressed conditions together with low sympathetic reactivity and high parasympathetic reactivity to stress (Koolhaas et al., 1999; Koolhaas, 2008). Of relevance to this section, a number of differences in immune function have been observed between coping styles (Koolhaas, 2008). Pigs with a reactive coping style express lower cellular immunity in vitro but higher humoral immunity following vaccination with keyhole limpet hemocyanin, in comparison to proactive coping pigs (Koolhaas, 2008). In the period prior to vaccination with tetanus toxoid and again after the peak of the immune response, proactive pigs exhibit a pattern of heightening inflammatory defense and tissue repair (Oster et al., 2015). In teleological terms, this pattern is considered to align with the heightened risk of injury accompanying the fight or flight character of the proactive coping style (Korte et al., 2005). In similarity with the studies of Cole and colleagues cited above, the effects of coping style on immune responses in pigs may arise from phenotypic effects of stress reactivity. The relative contribution of adrenergic activity to the immune response profiles seen in coping phenotypes has not been described, although in other studies epinephrine and norepinephrine have been found to promote an innate immune bias in pigs (Reiske et al., 2020) (however see Bacou et al., 2017). In contrast to associations between FS and production traits in cattle, genetic correlations between coping style as scored by back test and production traits in pigs are negligible (Velie et al., 2009; Iversen et al., 2017).

Together these findings suggest that heightened adrenergic activity can induce short-term bias and long-term programming of immune function toward an inflammatory phenotype with reduced antibody mediated adaptive immune function. The effects of catecholamines on immune functions are complex, and norepinephrine and epinephrine can exert contrasting effects on the inflammatory bias of macrophages via their independent actions on alpha and beta adrenoceptors (Barnes et al., 2015; Bacou et al., 2017). This divergence could lead to differences between the long-term effects of adrenergic tone and acute effects of adrenergic discharge during acute environmental challenge. Recent studies indicate that dopamine released from SNS within peripheral tissues is an important modulator of immune function (Matt and Gaskill, 2019; Broome et al., 2020) and therefore also deserves attention in studies on immune functions associated with FS. Activity of the parasympathetic nervous system also modulates immune function, for example, via the cholinergic anti-inflammatory reflex, thus providing an additional layer of autonomic nervous system modulation of immune responses (Kenney and Ganta, 2011), that furthermore can differ between individuals as illustrated by studies on coping styles (Koolhaas, 2008).

\subsection{Affective States}

Empirical (Lee et al., 2018) and theoretic (Boissy, 1995) studies indicate that temperament influences the affect state of cattle. Norepinephrine is an important neurotransmitter within the CNS with involvement in cognition, attention, vigilance, and affect (Coull et al., 1997; Kreibig, 2010; Kleckner and Quigley, 2015). Affect is a psychological state usually described as having two aspects; hedonic valence and arousal (Russell and Barrett, 1999; Mendl et al., 2010; Kremer et al., 2020; Mendl and Paul, 2020b). Valence describes attractiveness or aversiveness, and arousal describes the physiological and psychological activation that can accompany engagement with situations, objects or events in the internal or external environments. Affect is a system property arising from central processing of afferent inputs from the peripheral nervous system and from blood-borne messengers (Kleckner et al., 2017; Dantzer et al., 2018; Quigley et al., 2021). This "system property" concept is supported by studies of affective responses to electrical stimulation and microinjection of neurotransmitters into individual neurons within the nucleus accumbens and the amygdala in rats (Berridge, 2019). Affective responses cannot be repeatably titrated by incremental doses of stimulation. Rather, the affective response to any quantum of stimulus varies in accord with concurrent functional states associated with internal and external conditions of the animal, such as environmental context, anxiety, hunger or thirst (Kleckner and Quigley, 2015; Berridge, 2019; Hoemann et al., 2020).

The affective state of the animal is continuously present and dynamically varies over time (Kremer et al., 2020; Mendl and Paul, 2020b). Although humans can at times be aware of their affective state, it is generally accepted that awareness is not necessary for affect to be present or for it to modulate behavioral, physiological or immune processes, and hence that affect is an important aspect of the mental state in farm animals (Kremer et al., 2020; Mendl and Paul, 2020b). Affect modulates psychological processes like cognition, and also modulates somatic processes through autonomic and motor neuron activities (Kleckner and Quigley, 2015; Kleckner et al., 
2017; Mendl and Paul, 2020a). As a consequence, behavioral, physiological, and psychological activities (especially cognition) can serve as proxies for assessing affective states in farm animals (Mendl et al., 2009; Crump et al., 2018; Mattiello et al., 2019). A very large number of physiological changes have been correlated with affect (Kreibig, 2010; Kleckner and Quigley, 2015) and have attracted attention as potential measures of affect because of their relative ease of measurement. Heart rate variability and pre-ejection period of the heart contraction cycle are reduced by arousal (Cacioppo et al., 1994; von Borell et al., 2007). Parasympathetic and sympathetic activities exert mixed influences on heart function and on most other physiological activities (Berntson et al., 1991); however pre-ejection period has some utility as a "pure" measure of sympathetic influence and respiratory sinus arrhythmia as a pure measure of parasympathetic influence on heart function in humans (Cacioppo et al., 1994; Quigley and Stifter, 2006; Hoemann et al., 2020). Release of epinephrine from the adrenal medulla provides an additional level of stimulation of heart function and provides feedback to the central nervous system via stimulation of the vagus to further modify affective state (Miyashita and Williams, 2006). Notwithstanding the associations seen between autonomic nervous system activities and affective states, neither valence nor arousal exhibit one-to-one mapping to particular autonomic activities. Thus, a particular autonomic response can be seen in a range of affective state states (Kleckner and Quigley, 2015).

Although dynamically variable, valance and arousal have a tendency over time to return toward a balancing range of core affect that is characteristic for an individual. In humans, differences between individuals in this settling point are recognized as dispositions and traits such as dispositional optimism, dispositional happiness, and trait anxiety (Kremer et al., 2020). The long term balance of positive vs. negative affect is considered to be a measure of happiness in animals (Webb et al., 2018) and to be indicative of positive welfare (Lawrence et al., 2019). At present, methods for assessing affective states in farm animals are not sufficiently sensitive to detect long term differences between individuals in the balancing range of core affect in resting states (Mendl and Paul, 2020b). It is usually considered that the influence of affect on mental, behavioral, and somatic activities serves a homeostatic function with consequences for the welfare of the animal (Boissy et al., 2007; Lawrence et al., 2019; Mendl and Paul, 2020b). A role for affect in maintaining homeostasis is welldescribed in the literature. Two points from this discussion are of importance to the temperament syndrome associated with FS. Firstly, bi-direction interactions between central processes including affect and cognition and peripheral functions of the animal (Kleckner et al., 2017; Dantzer et al., 2018; Quigley et al., 2021) are mediated in part by adrenergic activities (Coull et al., 1997; Kreibig, 2010; Kleckner and Quigley, 2015). Secondly, it is likely that consistent individual differences in baseline core affect and in dynamic affective states associated with environmental challenges co-vary with FS (Boissy, 1995; Kremer et al., 2020).

\subsection{Summary of Adrenergic Effects}

SNS and AHS, through innervation of somatic tissues and via systemic release of catecholamines from the adrenal medulla into the bloodstream, contribute to the homeostatic balance of metabolism, body composition, tissue perfusion, immune function, and affective state. Studies in a number of species including beef cattle suggest that basal (tonic) activity varies between individuals and contributes to differences in basal metabolic rate, core body temperature, allocation of nutrients to defense vs. anabolic functions, and bias in the immune system toward innate inflammatory activity in priority over adaptive immune functions. In view of the homeostatic role of adrenergic activities in the resting state and in response to perceived threats from the internal and external environment, the next section addresses models of homeostatic regulation that may help illuminate the way traits associated with flightiness tend to persist across the life of the animal despite short and long term environmental fluctuations.

\section{REGULATION OF HOMEOSTASIS}

For an animal to survive and thrive requires maintenance of morphological and physiological conditions across organizational levels extending from intracellular processes to the whole organism (Chovatiya and Medzhitov, 2014). Cannon used the term homeostasis to describe a state or condition of the body, rather than the processes by which a state is maintained:

\begin{abstract}
"The constant conditions which are maintained in the body might be termed equilibria. That word, however, has come to have fairly exact meaning as applied to relatively simple physico-chemical states, in closed systems, where known forces are balanced. The coordinated physiological processes which maintain most of the steady states in the organism are so complex and so peculiar to living beings-involving, as they may, the brain and nerves, the heart, lungs, kidneys, and spleen, all working cooperatively-that I have suggested a special designation for these states, homeostasis. The word does not imply something set and immobile, a stagnation. It means a condition-a condition which may vary, but which is relatively constant."
\end{abstract}

Thus, Cannon suggested that homeostasis is not a single condition but rather that a number of states exist within the body that are each maintained in a homeostatic balance. In contemporary terms, homeostatic states and variables like psychological affect and body temperature are each regulated by a suite of effectors that actively maintain the state or regulated variable within a range of values (Goldstein, 2003; Ramsay and Woods, 2014; Kotas and Medzhitov, 2015; Goldstein and Kopin, 2017; Ye and Medzhitov, 2019). Opposing effectors are usually not simultaneously active, thereby exhibiting Sherrington's principle of reciprocal inhibition (Sherrington, 1913; Bauman, 2000; Ramsay and Woods, 2014), although exceptions do occur especially during chronic stress and in autonomic control of some organ functions (Berntson et al., 1991, 1993; Goldstein, 2003). Sensory pathways control the activity of effectors via feedback 
or feedforward to provide inhibition or activation of effectors (Bauman, 2000; Ramsay and Woods, 2014; Goldstein, 2019; Ye and Medzhitov, 2019). Romanovsky (2018) describes the suite of effectors that influence a state or variable as constituting a dynamic confederation of independent controllers. Importantly, afferent signals from sensors within effector pathways (e.g., from temperature sensors or baroceptors) are not integrated within a central homeostat (e.g., thermostat or barostat) to generate an integrated mean value (e.g., core body temperature, blood pressure). Nor is there a process by which such a putative mean value is compared to a central reference value (Romanovsky, 2018). Thus, states and variables are not regulated around physiological set points but tend to be maintained within a balancing range as an outcome of the activity of the confederation of controllers (Joyner and Limberg, 2014; Ramsay and Woods, 2014; Romanovsky, 2018). As a consequence, a sensor for an outcome state or variable is not necessary for the state or variable to (appear to) be regulated (Wirtshafter and Davis, 1977; Goldstein, 2003, 2019; Ramsay and Woods, 2014). Indeed, it is not the physiological variable that is regulated. It is the activity of each effector within the confederation of controllers that is regulated through proximate pathways of activation and inhibition. The clinically measured physiological variable (e.g., body temperature, blood pressure) emerges as a system property of the concerted activity of the controllers. Detailed accounts for body temperature and blood pressure regulation are provided by Romanovsky (2018) and Joyner and Limberg (2014). As discussed in more detail below, activity of effectors can be influenced by genetic, epigenetic, pharmacological, and short-acting physiological messengers that in concert contribute to characteristic differences seen between individuals. For the current discussion, this general feature of homeostatic regulation indicates that a sensor of affect (or of a higher order characteristic of the animal such as temperament) is not necessary for affect to (appear to) be a regulated state.

Effectors and sensors operate within the context of available resources. These resources provide a buffer against change in the state or variable by providing a reserve that can be drawn down or a sink (including excretion) that can accommodate excess (Cannon, 1929; Goldstein and Kopin, 2017; Ye and Medzhitov, 2019). Resources available to buffer the state or variable can take many forms and include chemical [e.g., pH buffering via carbonic acid $\left(\mathrm{H}_{2} \mathrm{CO}_{3}\right)$ and bicarbonate anion $\left.\left(\mathrm{HCO}^{-}\right)\right]$, physical (e.g., subcutaneous fat), psychological (e.g., competencies), social (e.g., presence and behavior of conspecifics), and other external conditions in the environment (e.g., shade, a warm den). Buffers can also act across generations. For example, in most mammals the mother enters a state of negative energy balance in early lactation and draws on her own body reserves to buffer the neonate against environmental variation in availability of energy in the mother's diet (Bauman, 2000). This transgenerational transfer of resources is evident in beef cows during lactation. Indeed, there is little genetic potential to select beef cattle for heavy calf weaning weight without penalty to cow body weight during periods of seasonal feed scarcity (Meyer and Colditz, 2015) illustrating that buffers confer robustness of physiological processes to the effects of environmental fluctuations.
From studies in developmental biology, it was recognized that states are also regulated over extended periods of time during ontogenetic progression along a developmental trajectory. Waddington termed the processes that regulate the flow of form and function along a trajectory or toward a new state, homeorhesis (Waddington, 1957). Many ontogenetic developments and life cycle transitions also occur in postnatal life and are regulated by homeorhetic processes. A detailed account of homeorhetic regulation of the transitions in tissue structure and metabolic functions that occur during development and maintenance of pregnancy and lactation in the dairy cow has been developed by Bauman and colleagues (Bauman and Currie, 1980; Bell and Bauman, 1997; Bauman, 2000). During lactogenesis and early lactation, changes in circulating concentrations of prolactin, growth hormone, glucocorticoids, insulin-like growth factor-1 and thyroid hormones induce organ-specific changes in expression of genes, expression and binding kinetics of receptors, and activity of signal transduction pathways. For instance, the lipolytic effect of betaadrenergic stimulation of adipocytes doubles during lactation, in comparison with the non-pregnant state in ewes (Guesnet et al., 1987) and cows (Baumgard et al., 2017). Insulin sensitivity of tissues also changes leading to decreased lipogenesis and decreased uptake of preformed fatty acids in adipose tissue, decreased glucose uptake in skeletal muscle and increased gluconeogenesis in liver which together lead to decreased glucose utilization by insulin-responsive non-mammary tissues (Bauman, 2000). These tissue-specific changes support the new physiological state of lactation (for reviews see Bauman, 2000; Baumgard et al., 2017; Habel and Sundrum, 2020). In this new state, physiological (and behavioral) variables are shifted to a new homeostatic range. The concept of homeorhesis has been extended to describe post-natal growth trajectories of cattle (Bauman et al., 1982) and coordinated responses during climatic adaptation (Collier et al., 2009) and immune function (Colditz, 2004). Mrosovsky (1990) suggested that these coordinated postnatal changes in homeostatic states could be better described by the term rheostasis.

The changes in pregnancy and lactation illustrate that homeostasis is a dynamic outcome that can be modulated over developmental, seasonal and short-term timeframes through genetic and epigenetic programming of the effectors that control physiological variables. Homeorhesis is used to describe the processes that contribute to the tendency for the trajectory of certain traits to be robust to genetic and environmental fluctuations (Waddington, 1957; Strandberg, 2009; Bateson and Gluckman, 2011). Nonetheless, an animal's phenotype also exhibits plasticity in the face of some transient or persistent environmental perturbations (Bateson and Gluckman, 2011). Many of the moment-to-moment and day-to-day excursions in physiological variables occur in anticipation of a physiological demand through actions of the autonomic nervous system (Goldstein, 2003). Sterling and Eyer (1988) introduced the term allostasis meaning stability through change to describe both short-term anticipatory physiological regulation via the ANS and the compensatory changes that occur during persistent environmental perturbations and disease processes (Goldstein, 
2003; McEwen and Wingfield, 2003; Korte et al., 2007; Koolhaas et al., 2011). A critique of allostasis is beyond the scope of the current review (see McEwen and Wingfield, 2010; Ramsay and Woods, 2014), and the concept is mentioned here to highlight that homeostatic balance is achieved through a dialogue between homeorhesis and allostasis (Colditz, 2020). Robustness and plasticity describe relative positions on a continuum (rather than being synonyms for a nature-nurture dichotomy), while the terms homeorhesis and allostasis provide descriptors of tendencies for effectors controlling form and physiological functions to be robust or plastic to environmental influences (Bateson and Gluckman, 2011; Colditz, 2020). The tendency for traits through which temperament is expressed to persist throughout the life of the animal underpins the homeorhetic account of temperament described next.

\section{DEVELOPMENT AND REGULATION OF FS AND ASSOCIATED TRAITS}

\subsection{Persistence of Behavioral and Somatic Expressions of Temperament}

The exquisite capacity for dynamic adjustments of behavior, metabolic activity, and immune function to achieve homeostatic balance in the face of changing environmental conditions draws attention to the paradoxical tendency for some characteristics of the animal to persist despite environmental fluctuations. As noted in the introduction, temperament is conceptualized in operational terms as the persistence of behavioral activity across time and across contexts (Lyons et al., 1988; Dingemanse et al., 2010; Stamps J. and Groothuis, 2010; MacKay and Haskell, 2015; Finkemeier et al., 2018). In accord with this characterization, persistence of individual differences between cattle in FS have been reported in a number of studies (Burrow and Dillon, 1997; Curley K. O. et al., 2006; Kilgour et al., 2006; Petherick et al., 2009b; Cafe et al., 2011b). While absolute values can vary between measurement days and can decrease with habituation to repeated handling through yards, the relative performance of individuals within a cohort tends to be fairly stable, especially for flighty animals with high FS (Cooke et al., 2009; Petherick et al., 2009b; Cafe et al., 2011b). Indeed, it is the persistence of relative performance within a contemporary group that is considered to characterize temperament (Lyons et al., 1988; Stamps J. and Groothuis, 2010). Notwithstanding the influence on FS of habituation to handling, studies on the behavioral responses to proximity of humans suggest that reactivity of cattle to the presence of humans is not strongly associated with FS (Kilgour et al., 2006; Cooke et al., 2009; Petherick et al., 2009b). This observation draws attention to the difference between transient behavioral expressions of temperament and the persistent underlying processes that sculpt the expressions of temperament. In studies on beef cattle managed at pasture, animals are typically handled through yards for assessment of FS at frequencies less than once every 30-60 days (Petherick et al., 2009b; Cafe et al., 2011b). Thus, the behavioral flight response to handling is a brief and infrequent event in comparison with the quotidian challenges of daily life. Furthermore, physiological responses to handling and transport including changes in cortisol, epinephrine, NEFA, and body temperature tend to be transient and return to pre-challenge values within minutes to hours (Curley et al., 2008; Cafe et al., 2011a; Lees et al., 2020). In contrast to the transience of these behavioral and physiological expressions of temperament, other traits associated with FS such as body weight, growth rate, metabolic rate, core body temperature, intramuscular fat deposition, and some immune functions are manifestations of persistent expression of metabolic functions and resource allocation priorities. The persistent whole-of-body association of flightiness with behavioral and physiological functions could be consistent with flighty temperament constituting a homeorhetically regulated state of the animal (Colditz, 2020; Supplementary Material). How might homeorhetic processes shape the expression of these traits?

\subsection{Homeorhetic Regulation of Temperament Traits}

Two types of homeorhetic regulation are relevant to temperament in cattle: (1) top down organization by the central nervous system of functions in somatic tissues that is coupled to external environmental cues; and (2) multiplex regulation integrating internal and external cues via dialogue between the central nervous system and somatic tissues providing both top down and bottom up inputs to the regulated physiological state. Top down regulation by a central controller in response to an external cue has recently been proposed for regulation of photoperiodism in sheep and other mammals by the circadian genes $B M A L 2$, and $D E C 1$, through their activating and suppressive effects on EYA3 in the pars tuberalis of the pituitary gland (Wood et al., 2020). The authors suggest that regulation of EYA3 constitutes a flip-flop switch for transitioning between two stable states recognized as summer and winter physiology. Variation between animals in the characteristics of summer and winter physiology such as coat length might then be influenced by additional proximate regulators of individual traits in peripheral tissues. In this top down model, regulation lies within the activity of the pituitary in response to day length signals it receives from the external environment. In contrast, in the multiplex model of homeorhesis provided by lactation, hormones including prolactin, growth hormone, glucocorticoids, insulin-like growth factor-1, and thyroid hormones produced both centrally and in peripheral tissues create an endocrine environment that modifies the expression of genes and the functions of pathways that provide the homeostatic settings for metabolic activities throughout the animal. Thus, visual and tactile stimuli from the external environment are integrated with neural and somatic signals from the internal environment in maintenance of the physiological state of lactation (Akers et al., 2000; Bauman, 2000; Armstrong, 2015). Within this multiplex hormonal environment, lactation performance is influenced by numerous genes influencing hormonal regulation, metabolism, and mammary gland function. Under the additional influence of availability of environmental resources, lactational performance is expressed as a continuous trait. Thus, the trait 
"lactation performance" is the expression of a physiological state recognized as "lactation" that is not controlled by a single regulator but is the summation of a whole-of-animal condition. These two models of homeorhetic regulation raise the question as to whether the physiological, behavioral, and immune characteristics of cattle with flighty temperament follow a central top-down model initiated by external environmental cues (such as proximity of humans) or multiplex integration of top-down and bottom-up messaging. This question is examined further in Section 5.5. While the persistence of the behavioral, physiological, and immunological expressions of flighty temperament are in accord with the homeorhetic model (Colditz, 2020), there remains a need for a mechanistic account of the developmental architecture of temperament to better understand how the stable patterning of temperament traits arises. Four timeframes for patterning are evident (Lyons et al., 1988; Stamps J. A. and Groothuis, 2010; Mason and Capitanio, 2012; Schuett et al., 2013; Stamps and Biro, 2016; Moldoff and Westneat, 2017), as described next.

\subsection{Patterning of FS and Its Associated Traits}

The patterning of tissue structure and function during ontogeny can have life-long influences on the expression of traits. This phenomenon has attracted particular attention in farm animals through the patterning of traits known as domestication syndrome. The cardinal sign of domestication in vertebrates is a reduction in fearfulness (Price, 1999; Wilkins, 2020). Accompanying the increase in tameness is a suite of behavioral and morphological changes including smaller jaws and teeth, wider heads, floppy ears, altered coat colors, smaller brains, reduced stress responsiveness, an extended timeframe during which socialization can occur and more frequent female sexual cycles than occur in wild progenitors (Trut et al., 2009). Deficits in activity of gene regulatory networks influencing development of the neural crest during embryogenesis have been proposed to link these domestication syndrome traits (Wilkins et al., 2014). Neural crest derivatives include the adrenal medulla and nerves of the autonomic and enteric nervous systems. Expression of homeobox gene $P H O X 2 B$ supports expression of glial-derived neurotrophic factor and MASH1 which regulate development of autonomic tissues and the enteric nervous system in the developing embryo. At this developmental stage, Phox $2 b$ protein is necessary for expression of tyrosine hydroxylase and dopamine- $\beta$-hydroxylase and is described as an essential determinant of the vertebrate noradrenergic phenotype (Pattyn et al., 1999).

A second phase of ontogenetic patterning that occurs later in fetal development has been demonstrated by studies of the effect of prenatal maternal stress on FS in calves. Repeated transport of brahman cows for $2 \mathrm{~h}$ at $60 \pm 5,80 \pm 5,100 \pm 5,120 \pm$ 5 , and $140 \pm 5 \mathrm{~d}$ of gestation was associated with a significant increase in FS and basal cortisol in calf progeny in comparison to controls (Littlejohn et al., 2016). Analysis of genome-wide distribution of differential DNA methylation (hypermethylation and hypomethylation) in peripheral blood leukocytes revealed alterations in canonical pathways of behavior, stress responses, metabolism, and immune function (Littlejohn et al., 2018). In a more focused analysis, differential methylation was observed in pathways involved in opioid signaling, corticotropin releasing hormone signaling, dopamine signaling, serotonin signaling, and GABA signaling (Littlejohn et al., 2020). Activity of the innate immune system was also studied in a subset of these calves by intravenous challenge with endotoxin (LPS). Prior to challenge, TNF- $\alpha$ and IL- 6 were higher and IFN- $\gamma$ lower in prenatally stressed calves. In contrast to the larger study population (Littlejohn et al., 2016), cortisol did not differ prior to challenge but responses were higher post challenge in pre-natally stressed calves. There was also a tendency for baseline rectal temperature to be higher in pre-natally stressed calves $(P=0.051)$. Adrenergic activity has not been described in these studies. When female progeny were assessed at 5 years of age, the pattern of change in DNA methylation as animals aged differed between prenatal treatments illustrating the persistence of effects of prenatal stress (Cilkiz et al., 2020).

Ontogenetic patterning in embryonic and fetal life are strong examples of homeorhetic regulation. The studies of Cole and colleagues (Irwin and Cole, 2011; Fredrickson et al., 2015; Cole, 2019) discussed in Section 3.3 illustrate a third time frame for patterning. The shift in immune function under the burden of environmental stressors provides a canonical example of phenotypic plasticity associated with allostatic reprogramming in post-natal life (McEwen, 1998). The persistency of the stress-induced immune phenotype and its associated changes in metabolic function are recognized as the basis for a stable dyshomeostasis (Thorp and Schlaich, 2015).

Learning during past-natal life provides a fourth pathway for patterning of behaviors. Persistent patterns of behavior can be acquired through a range of learning processes including imprinting, classical (Pavlovian) conditioning and instrumental learning (Goldstein, 2019). The pervasiveness of post-natal learning in modifying phenotype is illustrated by Pavlovian conditioning of immune functions (Colditz, 2008). All aspects of innate and adaptive immune functions so-far examined as well as many endocrine activities can be entrained through classical conditioning paradigms to be re-enlisted (re-expressed) when the animal is exposed at a later time to the conditioning stimulus, such as a sound, sight, odor, touch or taste, that was used in the training paradigm (Husband, 1993; Hadamitzky et al., 2020). The distinction between patterning of immune activities as a consequence of exposure to environmental stressors described in the preceding paragraph and Pavlovian conditioning is the need in the former example for an immune stimulus to reactivate the patterned immune function, whereas eliciting stimuli in behavioral conditioning are not molecular structures recognized by cells of the immune system. To emphasis this distinction, Pavlovian conditioning of immune function is also termed behavioral conditioning. Behavioral conditioning entails neural processing (Koren et al., 2020) and provides a further example of the anticipatory regulation Sterling and Eyer termed allostasis (Sterling and Eyer, 1988). Post-natal learning and experience have been found to induce plasticity of temperament in a number of species (Lyons et al., 1988; Stamps J. A. and Groothuis, 
2010; Schuett et al., 2013; Stamps and Biro, 2016; Moldoff and Westneat, 2017; Capitanio and Mason, 2019). Cattle can readily be habituated to handling and the presence of humans, however the failure of habituation to eliminate relative differences between animals in the FS test provides a strong argument that persistent learned behaviors play little role in the temperament syndrome associated with FS (Petherick et al., 2009b; Cafe et al., 2011b; Cooke, 2014).

Mason and Capitanio (2012) summarize developmental patterning as a process that is enabled by an ecologically appropriate environment which supports genome environment interactions that are "customary" of the evolutionary history of the species. The foreshortening of the recent evolutionary history of beef cattle by artificial selection creates challenges for the design of environments and management practices to deliberately nurture ontogenetic development of temperament traits that are adaptive for contemporary management environments.

\subsection{GWAS Studies of FS}

Genome-wide association studies (GWAS) in cattle phenotyped for FS can help cast some light on the influence of genes on ontogeny and mature function in the temperament syndrome. Single nucleotide polymorphisms (SNP) pointing to candidate genes associated with FS have been identified by several groups. Candidates include BARHL2, MAGEL2, NDN, SNRPN (Costilla et al., 2020; Brahman and two tropical composite herds), NCKAP5, PARK2, ANTXR1, GUCY1A2, CPE, DOCK1 (Valente et al., 2016; Nallore), PWWP2A, GABRG2 (Chen et al., 2020; Brahman and Yunling), DRD3, HTR2A (Garza-Brenner et al., 2017; Charolais), POU1F1, DRD3, VWA3A, ZBTB20, EPHA6, SNRPF, NTN4 (Dos Santos et al., 2017; Guzerat), ACER3, VRK2, FANCL, SLCO3A1, NRXN3, EXOC4, CACNG4, and SLC9A4 (Paredes-Sánchez et al., 2020; Brahman) (Table 1). Hanna et al. (2014) identified candidate genes involved in sodium ion transport and voltage gated ion channel functions associated with subjectively scored temperament in Nellore Angus cross cattle. Thus, candidate genes differ between studies and between breeds of cattle. Where quantified, SNP contribute up to a few percent of additive genetic variation in FS (Dos Santos et al., 2017; Costilla et al., 2020). The large number of candidate genes and their small individual additive genetic variation in FS is in accord with the additive genetic variation seen in heritability estimates of FS (Haskell et al., 2014). A theme of involvement in neural development and synaptic function is evident amongst the candidates. A notable absence from this list of candidates are SNP in genes encoding adrenergic receptors or enzymes tyrosine hydroxylase and dopamine- $\beta$-hydroxylase involved in the dopaminenorepinephrine-epinephrine synthesis pathway, which harbor known polymorphisms in cattle ( $\mathrm{Hu}$ et al., 2010; LourencoJaramillo et al., 2012). For a review of candidate genes associated with other behavioral traits in cattle see Friedrich et al. (2015).

\subsection{Summary of Regulation of Flightiness}

GWAS studies point to a prominent role of neural functions in generating the internal environment that tunes somatic activities into the characteristic patterns associated with flightiness in a top down manner. In this model, orchestration of temperament would lie within the neural activities modulated by structural and functional variation associated with the candidate genes identified by GWAS (e.g., Dos Santos et al., 2017; Costilla et al., 2020). Conversely, the potential for epigenetic patterning of peripheral tissue functions during ontogeny and mature life is well-recognized in the somatic activities associated with FS (Bell and Greenwood, 2016). In view of the importance of centripetal (afferent) nervous and blood borne messaging from peripheral tissues to the central nervous system (Kleckner et al., 2017; Dantzer et al., 2018; Quigley et al., 2021), a multiplex bi-directional model seems more plausible than a top down model driven by external environmental cues like proximity to humans. Thus, the persistent character of FS and its associated peripheral traits (Haskell et al., 2014) could arise from the influence of genetic variants (e.g., Dos Santos et al., 2017; Costilla et al., 2020) and prenatal epigenetic effects such as maternal stress on ontogenetic development in utero (Littlejohn et al., 2020), then be reinforced in postnatal life by feedback from peripheral tissues functioning within an autonomic and neurohormonal environment patterned by the earlier developmental programming (Kleckner et al., 2017; Dantzer et al., 2018; Quigley et al., 2021). The quantitative character of FS and its associated traits (Haskell et al., 2014) suggest that the balance of these influences may well differ between populations of cattle. In this multiplex homeorhetic model, temperament would lie within both the central neural functions modulating perception of the animal's internal and external environments providing top down regulation, and in the epigenetic settings in peripheral tissues providing tissuespecific regulation (Chovatiya and Medzhitov, 2014) and bottomup signaling to central processing functions (Kleckner et al., 2017). It is suggested here that adrenergic tone is an important intermediary within this dialogue.

Zuckerman (1995) suggests that temperament emerges from "chemical templates that produce and regulate proteins involved in building the structure of nervous systems and the neurotransmitters, enzymes, and hormones that regulate them." An attempt at one-to-one mapping of neutral processes such as neurotransmitter activity to temperament has long been discredited as molecular phrenology. The quantitative character of FS and the diversity of genes implicated with the trait is in accord with Zuckerman's model. Thus, while variation between individuals in baseline adrenergic tone and in adrenergic reactivity to perceived threats may provide a common link between traits associated with flightiness, a causal basis for variation in adrenergic tone within genes associated with adrenergic messaging may not be a prerequisite. Indeed, much of the variation between individuals that leads to variation in adrenergic tone is likely to lie outside the SNS and AHS systems.

\section{DISCUSSION}

Several further points are noteworthy. Early studies on temperament in cattle and other farm animal species focused 
TABLE 1 | Candidate genes associated with FS suggested in GWAS studies (Valente et al., 2016; Dos Santos et al., 2017; Garza-Brenner et al., 2017; Chen et al., 2020; Costilla et al., 2020; Paredes-Sánchez et al., 2020).

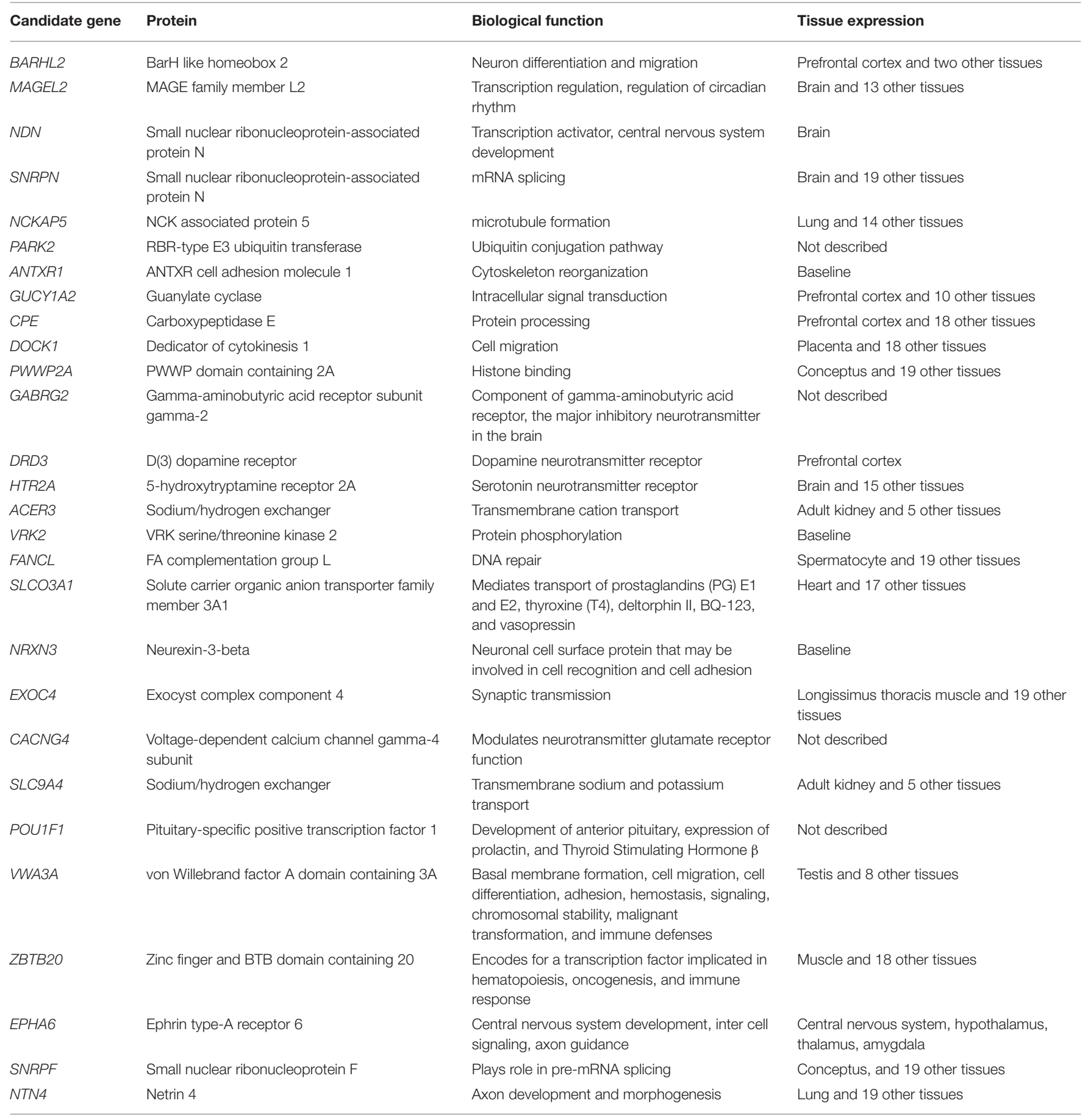

on consistent individual differences in behavior during handling (Tulloh, 1961; Burrow et al., 1988; Grandin, 1993). Nonetheless, it was also recognized that temperament is an enduring characteristic of the animal that persists in the absence of humans (Lyons et al., 1988; Sebastian et al., 2011) and which "represents an individual's basic stance toward continuing changes and challenges in its environment" (Mason, 1984), cited by (Lyons et al., 1988). Lyons (1989) goes on to add "In most naturalistic settings, the functioning of an individual's behavioral and physiological systems depends on multiple influences. An individual's characteristic temperament, its specific expectations and motivations, and salient environmental events interact to influence specific behavioral and physiological outcomes." The account of flightiness provided here is in accord 
with this concept of temperament as a pervasive whole-ofanimal attribute of the individual's process of environmental engagement (Capitanio and Mason, 2019). Indeed, the emergence of observed physiological states of the animal from the activity of Romanovsky's dynamic confederation of controllers (Romanovsky, 2018) provides a model of regulation that scales from proximate physiological variables like body temperature and blood pressure to intermediate states like psychological affect and whole-of-animal attributes like temperament.

Data on baseline values of physiological variables suggest that flightiness is associated with differences between animals at rest as well as when challenged by handling, confinement and the opportunity for escape. The influence of adrenergic activity on metabolic and immune functions described above together with persistent differences between individuals in resting sympathetic tone seen in humans suggest that persistent differences between individual cattle in adrenergic tone tune physiological activities that manifest as differences in metabolic rate, core body temperature, carcass composition, immune function, and perhaps affective disposition. In this respect, flightiness measured as escape from confinement in the chute can be considered to be but one manifestation of an underlying temperament trait that is also expressed through somatic and psychological functions of the animal. Thus, the underlying temperament trait measured by FS can be considered to be a whole-of-animal characteristic that is expressed at rest as well as during episodes of acute environmental challenge. The associations observed between FS and the expression of long-term behavioral activities in steers is in accord with this suggestion (MacKay et al., 2013). This whole-of-animal influence of temperament balances behavior, metabolism, and immune functions of each individual along an axis between active defense and generative flourishing. The remarkable point is that a continuous gradation along this axis should exist within a population of animals at rest. Further studies on baseline values of physiological variables are warranted, together with studies on the relationship between baseline adrenergic tone and adrenergic reactivity to environmental challenges such as handling. Examination of the influence of habituation of animals to handling on metabolic profiles associated with flightiness could be particularly informative. Failure of metabolic profiles to habituate despite behavioral habituation to handling would support the distributed multiplex homeorhetic model of temperament regulation. In addition, further studies on bias of immune responses toward inflammatory activity rather than adaptive immunity are warranted, together with further studies on associations of flightiness with immune competence (Hine et al., 2015, 2019). The influence of dopamine release as a component of adrenergic tone on immune function also deserves attention (Matt and Gaskill, 2019; Broome et al., 2020).

It follows that the position of an animal on the spectrum of flightiness does not describe the whole of the animal's temperament. This suggestion is in accord with the results of principal components analysis of behavioral tests in cattle (Kilgour et al., 2006) and with the more general conclusion drawn in behavioral ecology and psychology that temperament is a multidimensional attribute of the animal (Zuckerman, 1995; Réale et al., 2007; Finkemeier et al., 2018).

Associations between FS and HPA activity have been clearly demonstrated in numerous studies and the focus in this review on adrenergic function does not imply that HPA activity is not an important aspect of flighty temperament. Differing contributions of HPA, SNS, and AHS to host responses are observed in many stress paradigms (for review see Goldstein, 2003) and are a distinguishing feature of proactive vs. reactive coping styles (Koolhaas et al., 2010). Differences between individuals in activity of the parasympathetic nervous system (PNS) are also an important feature of coping styles (Koolhaas et al., 1999). PNS activity has attracted little attention in studies of FS. PNS and SNS exert one-dimensional reciprocal inhibition on the function of some organs; however a more complex pattern of autonomic control is usually observed (Berntson et al., 1991). PNS and SNS can exhibit coactivation, co-inhibition, and change in one while the other remains stable, as well as reciprocal inhibition. Thus, physiological functions occupy a two-dimensional "autonomic space" (Berntson et al., 1991) (Figure 2D). The autonomic space model is well-supported by studies of heart function in farm animals (von Borell et al., 2007) and physiological responses to affective experience in humans (Quigley and Stifter, 2006; Hoemann et al., 2020). Activity of PNS in FS warrants investigation as does the relative contribution of SNS and AHS activities at rest and in response to environmental challenges. To date, there have been few studies on the involvement of norepinephrine (SNS) in FS phenotypes. Dissection of the contribution of SNS and AHS activities should help illuminate the role of adrenergic tone in FS and it associated traits. Thus, it is not possible at present to speculate on whether differences occur between tonic activity of AHS (AHS tone) (Vicente et al., 2002), tonic activity of SNS (sympathetic tone) (Sundlöf and Wallin, 1977; Blum et al., 1989; Gazzola and Hunter, 1999) or whether there is a parallel tonic activity of both adrenergic pathways (adrenergic tone). Tone describes the intensity of neurotransmitter released over time. Discharge of neurotransmitters from the sympathetic nervous system is pulsatile and exhibits rhythms with a range of frequencies within an individual nerve fiber (Kenney and Ganta, 2011). Synchronization of discharge between fibers within a nerve bundle innervating a target organ, and between organs (such as synchronization between heart contraction and respiration) is thought to play an important role in modulating sympathetic tone and physiological activities of target organs (Barman and Kenney, 2007; Gilbey, 2007). It follows that variation between animals in propensity for synchronization of SNS discharge is an additional level of investigation that may reveal processes contributing to the temperament syndrome.

A further point of note is that activity of AHS, SNS, and PNS may differ between test paradigms used to measure behavioral activities and thereby contribute to differences seen between behavioral tests such as crush score and FS in their associations with production traits (Kadel et al., 2006; Cafe et al., 2011b; Haskell et al., 2014). Divergence of PNS, SNS, AHS, and HPA activity between behavioral tests is welldocumented in rodents (Goldstein, 2003; Koolhaas et al., 2010). 
A

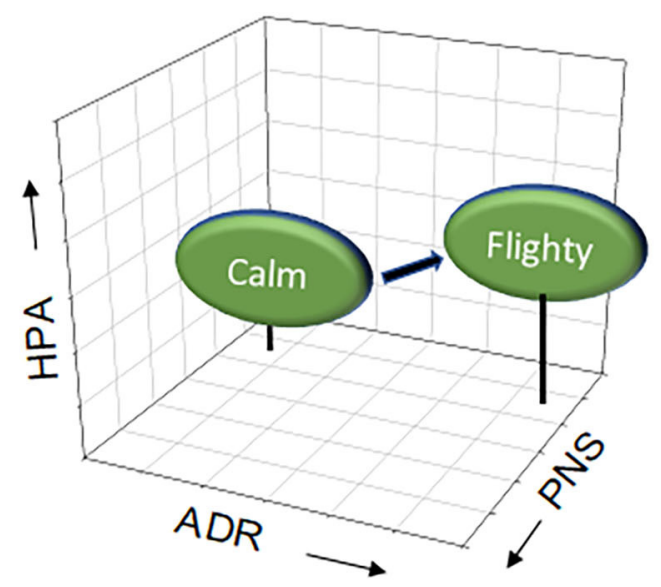

C

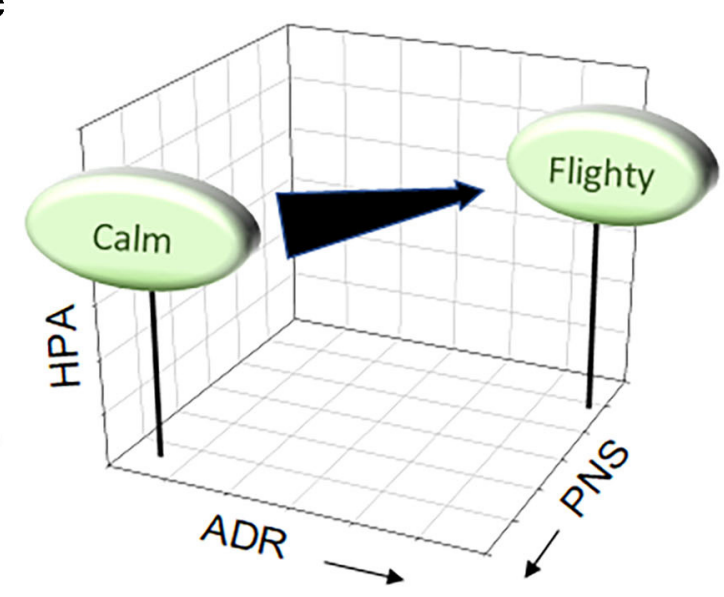

B

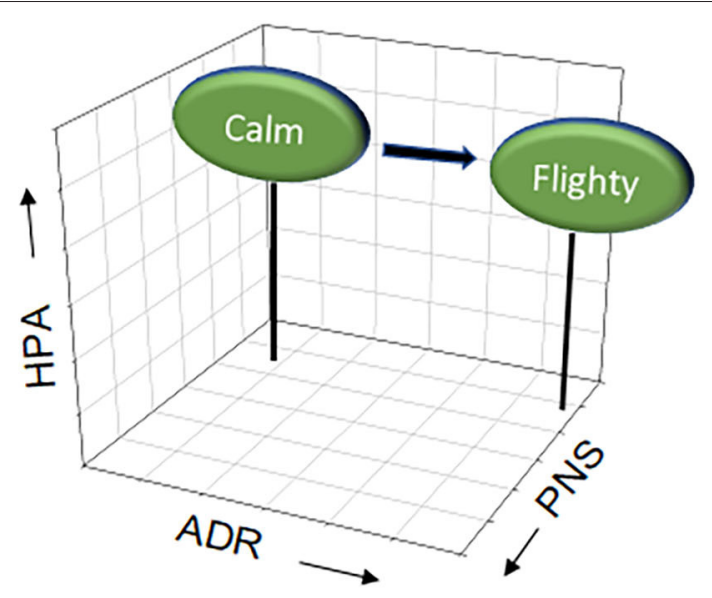

D

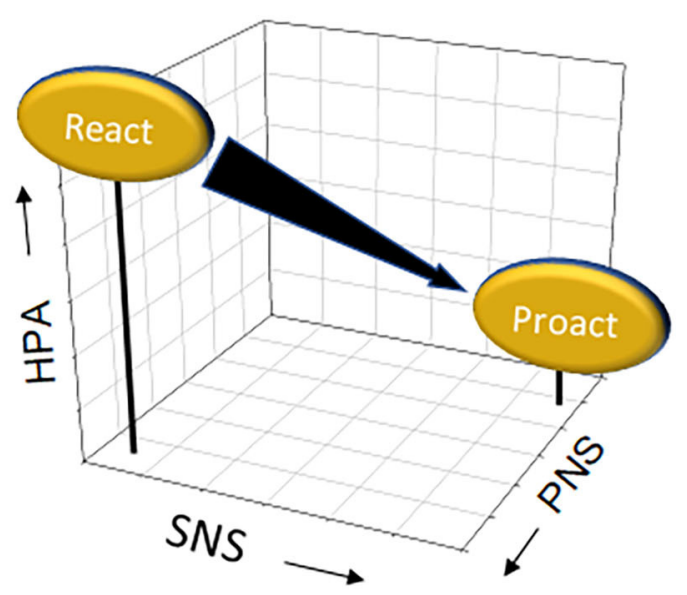

FIGURE 2 | Hypothetical location of cattle (A-C) and pigs (D) in physiological space. Animals occupy a 2 dimensional autonomic space created by activity of the sympathetic nervous system (SNS) and parasympathetic nervous system (PNS) illustrated by the x y plane (D) (Berntson et al., 1991). In panels (A-C), SNS activity is combined with adrenomedullary hormonal system (AHS) activity as adrenergic activity (ADR) in view of the limited studies in cattle on associations between flightiness and SNS activity. A third dimension to physiological regulation is provided by hypothalamic adrenal axis (HPA) activity ( $\mathrm{z}$ axis). In the resting state (A), ADR and HPA activity is elevated in flighty cattle (Flighty) in comparison to calm cattle (Calm). In the presence of environmental stressors such as transport or immune challenge with bacterial endotoxin (B), ADR and HPA activity in flighty cattle remains elevated. In contrast, HPA activity becomes elevated in calm animals with little change in ADR activity. The association between flightiness and position of cattle on the PNS axis has not be established and a hypothetical scenario is presented in (C). (D) illustrates the position of pigs with reactive (React) and proactive (Proact) coping styles within 3 dimensional autonomic and HPA space (Koolhaas et al., 1999). Individuals within a population fall along a vector (arrows) through 3-dimensional space between the extreme phenotypes illustrated as Calm and Flighty or Proactive and Reactive. Life history differences between species can also lead to species-typical differences in position within autonomic space (Capitanio and Mason, 2019).

The particular test paradigm used to assay temperament may in effect generate a transect through autonomic space along which individuals in a population are distributed (Figures $2 \mathrm{~A}-\mathrm{C}$ ). To the extent that genetic and epigenetic variations between individuals in their perception of the environment and in autonomic and HPA functions contribute to their position along a particular transect, different test paradigms may reveal different temperament types as illustrated by Figures 2B,D. Furthermore, not all temperament types as revealed by transects through autonomic space may be as strongly associated with consistent individual differences in metabolic and immune functions as is FS. Capitanio and Mason (2019) note from studies in wild and captive monkeys that consistent differences in autonomic function can occur between species as well as between individuals with a species. The dimensions of temperament that for many species are summarized as boldness, aggressiveness, reactivity, sociability, and exploration may reflect principal dimensions of environmental variability that are of ecological salience to the life history and eco-niche that a species occupies. Variation between individuals within a species points to temperament being a tuning factor that modulates the environmental fit of a population both within and across generations. A challenge for studies on temperament is to identify test paradigms that reflect the ecologically salient aspects of environment that over evolutionary time have exerted selective pressure on temperament in the species of interest. For beef cattle, the 
opportunity to escape from the perceived threat posed by isolation and confinement may fortuitously fulfill this role.

The multiplex model has implications for how the temperament trait associated with flightiness is defined and measured. If the trait lies not only within the neural functions (such as those predicted by candidate genes near SNP identified by GWAS) that generate perceptions of environmental threats but is also situated within the somatic (metabolic and immune) functions that generate afferent inputs to those neural functions, then measurement of the temperament trait may be improved by combining the behavioral escape response with measurements of immune and metabolic functions. Describing the trait solely by its behavioral dimension might miss some aspects of the underlying trait. Thus, characteristics such as immune function, body temperature, metabolic activity, and appetite (not discussed here) are not merely consequences of a neural top down driver of flightiness but are themselves attributes of the underlying temperament syndrome (Biro and Stamps, 2010). A challenge for animal scientists is to develop statistical models to integrate activity of the components of the temperament syndrome in a manner that adequately reflects the biological emergence of temperament within the animal.

The model of flightiness as a suite of processes situated within the architecture and activities of neural and somatic tissues is in accord with the Bayesian brain model of sensory perception and neural function (Kristiansen and Fernö, 2020), and the viewpoint of biology known as enactivism (Allen, 2018; Gefter, 2018; Colditz, 2020). These viewpoints have a long history in philosophy and biology, and align in general terms with a number of alternative accounts such as the organismic perspective described by Mason and Capitanio (2012).

Information on the association between FS and affective state is limited to one study, which provided evidence that flightiness is associated with increased arousal and a negatively valenced state during a threat perception test (Lee et al., 2018). Further work is warranted on the susceptibility of flighty animals to negative affective states during acute environmental challenge and their disposition to negative affectivity when at rest. In view of the importance of positive affective states to positive welfare (Lawrence et al., 2019) this question has important implications for the welfare of free ranging cattle at pasture as well as within the infrastructure of handling facilities and feedlots. Evidence in

\section{REFERENCES}

Akers, R. M., McFadden, T. B., Purup, S., Vestergaard, M., Sejrsen, K., and Capuco, A. V. (2000). Local IGF-I axis in peripubertal ruminant mammary development. J. Mammary Gland Biol. Neoplasia 5, 43-51. doi: 10.1023/A:1009563115612

Alexander, G., Bennett, J. W., and Gemmell, R. T. (1975). Brown adipose tissue in the new born calf (Bos taurus). J. Physiol. 244, 223-234. doi: 10.1113/jphysiol.1975.sp010793

Allen, M. (2018). The foundation: mechanism, prediction, and falsification in Bayesian enactivism. Comment on “Answering Schrödinger's question: a freeenergy formulation” by Maxwell James Désormeau Ramstead et al. Phys. Life Rev. 24, 17-20. doi: 10.1016/j.plrev.2018.01.007 mice indicates that negative affective states have a cumulative effect that decreases resilience to subsequent aversive events (Clarkson et al., 2020). A tendency toward negative affectivity in flighty cattle would provide an additional limit to their suitability for participation in the animal domestication niche of modern animal production.

In conclusion, a plausible scenario is that in beef cattle, fight or flight activity in the face of acute challenge as well as persistent differences in physiological functions such as metabolic rate, growth rate, rectal temperature, carcass composition, and immune competence are aspects of a flightiness temperament syndrome that is mediated in part via adrenergic tone. Nonetheless, adrenergic tone is but one of several neurosomatic axes influencing these traits. Variation between individuals in activity of these other axes together with variation in capacity of tissues to respond to adrenergic and non-adrenergic stimuli and to express downstream traits are likely to be additional sources of variation in the relationship between FS, production, health, and welfare.

\section{AUTHOR CONTRIBUTIONS}

The author wrote the article and approved the final version for publication.

\section{FUNDING}

This work was funded by the Commonwealth Scientific and Industrial Research Organisation (CSIRO) (internal funding, www.csiro.au/).

\section{ACKNOWLEDGMENTS}

Comments on an earlier draft of this review by Linda Cafe, Caroline Lee, Aaron Ingham, Jessica Monk, and two journal reviewers were grateful acknowledged.

\section{SUPPLEMENTARY MATERIAL}

The Supplementary Material for this article can be found online at: https://www.frontiersin.org/articles/10.3389/fanim. 2021.652306/full\#supplementary-material during lactation," in Knobil and Neill's Physiology of Reproduction, eds T. M. Plant, A. J. Zelezkni (Amsterdam: Elsevier/Academic Press), 527-563.

Bacou, E., Haurogné, K., Allard, M., Mignot, G., Bach, J. M., Hervé, J., et al. (2017). $\beta 2$-adrenoreceptor stimulation dampens the LPS-induced M1 polarization in pig macrophages. Dev. Comp. Immunol. 76, 169-176. doi: 10.1016/j.dci.2017.06.007

Badino, P., Odore, R., and Re, G. (2005). Are so many adrenergic receptor subtypes really present in domestic animal tissues? a pharmacological perspective. Vet. J. 170, 163-174. doi: 10.1016/j.tvjl.2004.05.015

Barman, S. M., and Kenney, M. J. (2007). Methods of analysis and physiological relevance of rhythms in sympathetic nerve discharge. Clin. Exp. Pharmacol. Physiol. 34, 350-355. doi: 10.1111/j.1440-1681.2007.04586.x 
Barnes, M. A., Carson, M. J., and Nair, M. G. (2015). Non-traditional cytokines: how catecholamines and adipokines influence macrophages in immunity, metabolism, and the central nervous system. Cytokine 72, 210-219. doi: 10.1016/j.cyto.2015.01.008

Bateson, P., and Gluckman, P. (2011). Plasticity, Robustness, Development, and Evolution. New York, NY: Cambridge University Press.

Bauman, D. E. (2000). "Regulation of nutrient partitioning during lactation: homeostasis and homeorhesis revisited," in Ruminant Physiology: Digestion, Metabolism, Growth, and Reproduction, ed P. B. Cronjé (Wallingford: CAB International), 311-328.

Bauman, D. E., and Currie, W. B. (1980). Partitioning of nutrients during pregnancy and lactation: a review of mechanisms involving homeostasis and homeorhesis. J. Dairy Sci. 63, 1514-1529. doi: 10.3168/jds.S0022-0302(80)83111-0

Bauman, D. E., Eisemann, J. H., and Currie, W. B. (1982). Hormonal effects on partitioning of nutrients for tissue growth: role of growth hormone and prolactin. Fed. Proc. 41, 2538-2544.

Baumgard, L. H., Collier, R. J., and Bauman, D. E. (2017). A 100-year review: regulation of nutrient partitioning to support lactation. J. Dairy Sci. 100, 10353-10366. doi: 10.3168/jds.2017-13242

Behrends, S. M., Miller, R. K., Rouquette Jr., F. M., Randel, R. D., Warrington, B. G., Forbes, T. D. A., et al. (2009). Relationship of temperament, growth, carcass characteristics, and tenderness in beef steers. Meat Sci. 81, 433-438. doi: 10.1016/j.meatsci.2008.09.003

Bell, A. W., and Bauman, D. E. (1997). Adaptations of glucose metabolism during pregnancy and lactation. J. Mammary Gland Biol. Neoplasia 2, 265-278. doi: 10.1023/A:1026336505343

Bell, A. W., and Greenwood, P. L. (2016). Prenatal origins of postnatal variation in growth, development, and productivity of ruminants. Anim. Prod. Sci. 56, 1217-1232. doi: 10.1071/AN15408

Benus, R. F., Bohus, B., Koolhaas, J. M., and Van Oortmerssen, G. A. (1991). Heritable variation for aggression as a reflection of individual coping strategies. Experientia 47, 1008-1019. doi: 10.1007/BF01923336

Berntson, G. G., Cacioppo, J. T., and Quigley, K. S. (1991). Autonomic determinism: the modes of autonomic control, the doctrine of autonomic space, and the laws of autonomic constraint. Psychol. Rev. 98:459-487. doi: 10.1037/0033-295X.98.4.459

Berntson, G. G., Cacioppo, J. T., and Quigley, K. S. (1993). Respiratory sinus arrhythmia: autonomic origins, physiological mechanisms, and psychophysiological implications. Psychophysiology 30, 183-196. doi: 10.1111/j.1469-8986.1993.tb01731.x

Berridge, K. C. (2019). Affective valence in the brain: modules or modes? Nat. Rev. Neurosci. 20, 225-234. doi: 10.1038/s41583-0190122-8

Biro, P. A., and Stamps, J. A. (2008). Are animal personality traits linked to life-history productivity? Trends Ecol. Evol. 23, 361-368. doi: $10.1016 /$ j.tree.2008.04.003

Biro, P. A., and Stamps, J. A. (2010). Do consistent individual differences in metabolic rate promote consistent individual differences in behavior? Trends Ecol. Evol. 25, 653-659. doi: 10.1016/j.tree.2010.08.003

Black, T. E., Bischoff, K. M., Mercadante, V. R. G., Marquezini, G. H. L., DiLorenzo, N., Chase Jr., C. C., et al. (2013). Relationships among performance, residual feed intake, and temperament assessed in growing beef heifers and subsequently as 3-year-old, lactating beef cows. J. Anim. Sci. 91, 2254-2263. doi: $10.2527 /$ jas.2012-5242

Blum, J. W., Schams, D., and Bruckmaier, R. (1989). Catecholamines, oxytocin, and milk removal in dairy cows. J. Dairy Res. 56, 167-177. doi: $10.1017 /$ S0022029900026388

Boisclair, Y. R., Johnston, K. B., Bauman, D. E., Crooker, B. A., Dunshea, F. R., and Bell, A. W. (1997). Paradoxical increases of circulating nonesterified fatty acids in somatotropin treated cattle undergoing mild disturbances. Domest. Anim. Endocrinol. 14, 251-262. doi: 10.1016/S0739-7240(97) 00021-0

Boissy, A. (1995). Fear and fearfulness in animals. Q. Rev. Biol. 70, 165-191. doi: $10.1086 / 418981$

Boissy, A., Fisher, A. D., Bouix, J., Hinch, G. N., and Le Neindre, P. (2005). Genetics of fear in ruminant livestock. Livest. Prod. Sci. 93, 23-32. doi: 10.1016/j.livprodsci.2004.11.003
Boissy, A., Manteuffel, G., Jensen, M. B., Moe, R. O., Spruijt, B., Keeling, L. J., et al. (2007). Assessment of positive emotions in animals to improve their welfare. Physiol. Behav. 92, 375-397. doi: 10.1016/j.physbeh.2007.02.003

Boles, J. A., Kohlbeck, K. S., Meyers, M. C., Perz, K. A., Davis, K. C., and Thomson, J. M. (2015). The use of blood lactate concentration as an indicator of temperament and its impact on growth rate and tenderness of steaks from Simmental+ù Angus steers. Meat Sci. 103, 68-74. doi: 10.1016/j.meatsci.2015.01.003

Bouwknecht, J. A., Olivier, B., and Paylor, R. E. (2007). The stress-induced hyperthermia paradigm as a physiological animal model for anxiety: a review of pharmacological and genetic studies in the mouse. Neurosci. Biobehav. Rev. 31, 41-59. doi: 10.1016/j.neubiorev.2006.02.002

Bronzo, V., Lopreiato, V., Riva, F., Amadori, M., Curone, G., Addis, M. F., et al. (2020). The role of innate immune response and microbiome in resilience of dairy cattle to disease: the mastitis model. Animals 10:1397. doi: 10.3390/ani10081397

Broome, S. T., Louangaphay, K., Keay, K. A., Leggio, G. M., Musumeci, G., and Castorina, A. (2020). Dopamine: an immune transmitter. Neural Regen. Res. 15, 2173-2185. doi: 10.4103/1673-5374.284976

Bruce, L. B. (1998). Effect of selenium on cold adapted beef cattle. Asian Aust. J. Anim. Sci. 11, 265-267. doi: 10.5713/ajas.1998.265

Bruno, K., Vanzant, E., Vanzant, K., Altman, A., Kudupoje, M., and McLeod, K. (2018). Relationship between quantitative measures of temperament and other observed behaviors in growing cattle. Appl. Anim. Behav. Sci. 199, 59-66. doi: 10.1016/j.applanim.2017.10.009

Burdick Sanchez, N. C., Carroll, J. A., Broadway, P. R., Hughes, H. D., Roberts, S. L., Richeson, J. T., et al. (2016). Cattle temperament influences metabolism: metabolic response to glucose tolerance and insulin sensitivity tests in beef steers. Domest. Anim. Endocrinol. 56, 85-95. doi: 10.1016/j.domaniend.2016.02.009

Burdick, N. C., Carroll, J. A., Hulbert, L. E., Dailey, J. W., Ballou, M. A., Randel, R. D., et al. (2011c). Temperament influences endotoxin-induced changes in rectal temperature, sickness behavior, and plasma epinephrine concentrations in bulls. Innate immun. 17, 355-364. doi: 10.1177/1753425910379144

Burdick, N. C., Carroll, J. A., Randel, R. D., Willard, S. T., Vann, R. C., Chase Jr., C. C., et al. (2011a). Influence of temperament and transportation on physiological and endocrinological parameters in bulls. Livest. Sci. 139, 213-221. doi: 10.1016/j.livsci.2011.01.013

Burdick, N. C., Randel, R. D., Carroll, J. A., and Welsh, T. H. (2011b). Interactions between temperament, stress, and immune function in cattle. Int. J. Zool. 2011:373197. doi: 10.1155/2011/373197

Burrow, H. M. (1997). Measurements of temperament and their relationship with performance traits of beef cattle. Anim. Breed. Abstr. 65, 477-495.

Burrow, H. M. (2001). Variances and covariances between productive and adaptive traits and temperament in a composite breed of tropical beef cattle. Livest. Prod. Sci. 70, 213-233. doi: 10.1016/S0301-6226(01)00178-6

Burrow, H. M., and Dillon, R. D. (1997). Relationships between temperament and growth in a feedlot and commercial carcass traits of Bos indicus crossbreds. Aust. J. Exp. Agric. 37, 407-411. doi: 10.1071/EA96148

Burrow, H. M., Seifert, G. W., and Corbet, N. J. (1988). A new technique for measuring temperament in cattle. Proc. Aust. Soc. Anim. Prod. 17, 154-157.

Cacioppo, J. T., Berntson, G. G., Binkley, P. F., Quigley, K. S., Uchino, B. N., and Fieldstone, A. (1994). Autonomic cardiac control. II. Noninvasive indices and basal response as revealed by autonomic blockades. Psychophysiology 31, 586-598. doi: 10.1111/j.1469-8986.1994.tb02351.x

Cafe, L. M., Robinson, D. L., Ferguson, D. M., Geesink, G. H., and Greenwood, P. L. (2011a). Temperament and hypothalamic-pituitary-adrenal axis function are related and combine to affect growth, efficiency, carcass, and meat quality traits in Brahman steers. Domest. Anim. Endocrinol. 40, 230-240. doi: 10.1016/j.domaniend.2011.01.005

Cafe, L. M., Robinson, D. L., Ferguson, D. M., McIntyre, B. L., Geesink, G. H., and Greenwood, P. L. (2011b). Cattle temperament: Persistence of assessments and associations with productivity, efficiency, carcass, and meat quality traits $1 . J$. Anim. Sci. 89, 1452-1465. doi: 10.2527/jas.2010-3304

Cannon, W. B. (1929). Organization for physiological regulation. Physiol. Rev. 9, 399-431. doi: 10.1152/physrev.1929.9.3.399

Capitanio, J. P. (2011). "Nonhuman primate personality and immunity: mechanisms of health and disease," in Personality and Temperament in 
Nonhuman Primates, eds A. Weiss, J. E. King, and L. Murray (New York, NY: Springer), 233-255.

Capitanio, J. P., and Mason, W. A. (2019). "Personality as adaptation: perspectives from nonhuman primates," in Using Basic Personality Research to Inform Personality Pathology, eds D. B. Samuel and D. R. Lynam (New York, NY: Oxford University Press), 219-236.

Careau, V., Thomas, D., Humphries, M. M., and Réale, D. (2008). Energy metabolism and animal personality. Oikos 117, 641-653. doi: 10.1111/j.0030-1299.2008.16513.x

Castanheira, M. F., Conceição, L. E., Millot, S., Rey, S., Bégout, M.-L., Damsgård, B., et al. (2017). Coping styles in farmed fish: consequences for aquaculture. Rev. Aquac. 9, 23-41. doi: 10.1111/raq.12100

Chen, Q., Zhang, F., Qu, K., Hanif, Q., Shen, J., Jia, P., et al. (2020). Genome wide association study identifies genomic loci associated with flight reaction in cattle. J. Anim. Breed. Genet. 137, 477-485. doi: 10.1111/jbg.12461

Chovatiya, R., and Medzhitov, R. (2014). Stress, inflammation, and defense of homeostasis. Mol. Cell 54, 281-288. doi: 10.1016/j.molcel.2014.03.030

Cilkiz, K. Z., Baker, E. C., Riggs, P. K., Littlejohn, B. P., Long, C. R., Welsh, T. H., et al. (2020). Genome-wide DNA methylation alteration in prenatally stressed Brahman heifer calves with the advancement of age. Epigenetics. doi: 10.1080/15592294.2020.1805694. [Epub ahead of print].

Clarkson, J. M., Leach, M. C., Flecknell, P. A., and Rowe, C. (2020). Negative mood affects the expression of negative but not positive emotions in mice. Proc. $R$. Soc. B 287:20201636. doi: 10.1098/rspb.2020.1636

Colditz, I. (2008). "The learnt phenotype: physiological, behavioural, and immunological adaptation to environmental stimuli," in AAWS International Animal Welfare Conference (Gold Coast, QLD). Available online at: http://citeseerx.ist.psu.edu/viewdoc/download?doi=10.1.1.523.5518andrep= replandtype $=$ pdf $($ accessed December 19, 2020).

Colditz, I. G. (2004). Some mechanisms regulating nutrient utilisation in livestock during immune activation: an overview. Aust. J. Exp. Agric. 44, 453-458. doi: 10.1071/EA02066

Colditz, I. G. (2020). A consideration of physiological regulation from the perspective of Bayesian enactivism. Physiol. Behav. 214:112758. doi: 10.1016/j.physbeh.2019.112758

Cole, S. W. (2014). Human social genomics. PLoS Genet. 10:e1004601. doi: 10.1371/journal.pgen.1004601

Cole, S. W. (2019). The conserved transcriptional response to adversity. Curr. Opin. Behav. Sci. 28, 31-37. doi: 10.1016/j.cobeha.2019.01.008

Cole, S. W., Levine, M. E., Arevalo, J. M., Ma, J., Weir, D. R., and Crimmins, E. M. (2015). Loneliness, eudaimonia, and the human conserved transcriptional response to adversity. Psychoneuroendocrinology 62, 11-17. doi: 10.1016/j.psyneuen.2015.07.001

Collier, R. J., Limesand, S. W., Rhoads, M. L., Rhoads, R. P., Baumgard, L. H., and Rauw, W. M. (2009). "Homeorhesis during heat stress," in Resource Allocation Theory Applied to Farm Animal Production, ed W. M. Rauw (Wallingford: CABI Publishing), 72-88.

Cooke, R. F. (2014). Bill E. Kunkle Interdisciplinary Beef Symposium: temperament and acclimation to human handling influence growth, health, and reproductive responses in Bos taurus and Bos indicus cattle. J. Anim. Sci. 92, 5325-5333. doi: 10.2527/jas.2014-8017

Cooke, R. F., Arthington, J. D., Araujo, D. B., and Lamb, G. C. (2009). Effects of acclimation to human interaction on performance, temperament, physiological responses, and pregnancy rates of Brahman-crossbred cows. J. Ani. Sci. 87, 4125-4132. doi: 10.2527/jas.2009-2021

Coombes, S. V., Gardner, G. E., Pethick, D. W., and McGilchrist, P. (2014). The impact of beef cattle temperament assessed using flight speed on muscle glycogen, muscle lactate, and plasma lactate concentrations at slaughter. Meat Sci. 98, 815-821. doi: 10.1016/j.meatsci.2014.06.029

Costilla, R., Kemper, K. E., Byrne, E. M., Porto-Neto, L. R., Carvalheiro, R., Purfield, D. C., et al. (2020). Genetic control of temperament traits across species: association of autism spectrum disorder risk genes with cattle temperament. Genet. Sel. Evol. 52, 1-14. doi: 10.1186/s12711-02000569-z

Coull, J. T., Frith, C. D., Dolan, R. J., Frackowiak, R. S. J., and Grasby, P. M. (1997). The neural correlates of the noradrenergic modulation of human attention, arousal, and learning. Eur. J. Neurosci. 9, 589-598. doi: 10.1111/j.1460-9568.1997.tb01635.x
Crump, A., Arnott, G., and Bethell, E. J. (2018). Affect-driven attention biases as animal welfare indicators: review and methods. Animals 8:136. doi: 10.3390/ani8080136

Curley Jr., K. O., Paschal, J. C., Welsh, T. H., and Randel, R. D. (2006). Technical note: exit velocity as a measure of cattle temperament is repeatable and associated with serum concentration of cortisol in Brahman bulls. J. Anim. Sci. 84, 3100-3103. doi: 10.2527/jas.2006-055

Curley, K. O., Neuendorff, D. A., Lewis, A. W., Cleere, J. J., Welsh Jr., T. H., and Randel, R. D. (2008). Functional characteristics of the bovine hypothalamicpituitary adrenal axis vary with temperament. Horm. Behav. 53, 20-27. doi: 10.1016/j.yhbeh.2007.08.005

Curley, K. O. J., Pfeiffer, C. E., King, D. A., Savell, J. W., Vann, R. C., Welsh Jr., T. H., et al. (2006). Relationships of cattle temperament and physiologic responses to handling during typical management situations. J. Anim. Sci. 84:32.

Dantzer, R., Cohen, S., Russo, S., and Dinan, T. (2018). Resilience and immunity. Brain Behav. Immun. 74, 28-42. doi: 10.1016/j.bbi.2018.08.010

Dingemanse, N. J., Kazem, A. J., Réale, D., and Wright, J. (2010). Behavioural reaction norms: animal personality meets individual plasticity. Trends Ecol. Evol. 25, 81-89. doi: 10.1016/j.tree.2009.07.013

Dos Santos, F. C., Peixoto, M. G., Fonseca, P. A., Pires, M. F., Ventura, R. V., Rosse, I. D, et al. (2017). Identification of candidate genes for reactivity in Guzerat (Bos indicus) cattle: a genome-wide association Study. PLoS ONE 12:e0169163. doi: 10.1371/journal.pone.0169163

Dunshea, F. R., and D’Souza, D. N. (2003). "Review: fat deposition and metabolism in the pig," in Manipulating pig Production IX., ed J. E. Paterson (Brisbane QLD: Australian Pig Science Association), 127-150.

Falck, B., Nystedt, T., Rosengren, E., and Stenflo, J. (1964). Dopamine and mast cells in ruminants. Acta Pharmacol. Toxicol. 21, 51-58. doi: 10.1111/j.1600-0773.1964.tb01768.x

Fell, L. R., Colditz, I. G., Walker, K. H., and Watson, D. L. (1999). Associations between temperament, performance and immune function in cattle entering a commercial feedlot. Aust. J. Exp. Agric. 39, 795-802. doi: 10.1071/ EA99027

Ferguson, D. M., Johnston, D., Burrow, H. M., and Reverter, A. (2006). "Relationships between temperament, feedlot performance, and beef quality," in Beef CRC, Australian Beef-The Leader Conference (Armidale), 161-165.

Fernandez-Novo, A., Pérez-Garnelo, S. S., Villagrá, A., Pérez-Villalobos, N., and Astiz, S. (2020). The Effect of stress on reproduction and reproductive technologies in beef cattle-a review. Animals 10:2096. doi: 10.3390/ani10112096

Finkemeier, M. A., Langbein, J., and Puppe, B. (2018). Personality research in mammalian farm animals: concepts, measures, and relationship to welfare. Front. Vet. Sci. 5:131. doi: 10.3389/fvets.2018.00131

Fordyce, G., Goddard, M. E., and Seifert, G. W. (1982). The measurement of temperament in cattle and the effect of experience and genotype. Proc. Aust. Soc. Ani. Prod. 14, 329-332.

Forkman, B., Furuhaug, I. L., and Jensen, P. (1995). Personality, coping patterns, and aggression in piglets. Appl. Anim. Behav. Sci. 45, 31-42. doi: 10.1016/0168-1591(95)00601-N

Francisco, C. L., Resende, F. D., Benatti, J. M. B., Castilhos, A. M., Cooke, R. F., and Jorge, A. M. (2015). Impacts of temperament on Nellore cattle: physiological responses, feedlot performance, and carcass characteristics. J. Anim. Sci. 93, 5419-5429. doi: 10.2527/jas.2015-9411

Fredrickson, B. L., Grewen, K. M., Algoe, S. B., Firestine, A. M., Arevalo, J. M., Ma, J., et al. (2015). Psychological well-being and the human conserved transcriptional response to adversity. PLoS ONE 10:e121839. doi: 10.1371/journal.pone.0121839

Friedrich, J., Brand, B., and Schwerin, M. (2015). Genetics of cattle temperament and its impact on livestock production and breeding-a review. Arch. Anim. Breed. 58, 13-21. doi: 10.5194/aab-58-13-2015

Gale, C. C. (1973). Neuroendocrine aspects of thermoregulation. Annu. Rev. Physiol. 35, 391-430. doi: 10.1146/annurev.ph.35.030173. 002135

Garza-Brenner, E., Sifuentes-Rincón, A. M., Randel, R. D., Paredes-Sánchez, F. A., Parra-Bracamonte, G. M., Vera, W. A., et al. (2017). Association of SNPs in dopamine and serotonin pathway genes and their interacting genes with temperament traits in Charolais cows. J. Appl. Genet. 58, 363-371. doi: 10.1007/s13353-016-0383-0 
Gazzola, C., and Hunter, R. A. (1999). Reducing metabolic rate by immunoneutralisation of catecholamines. Aust. J. Agric. Res. 50, 441-446. doi: 10.1071/A98153

Gazzola, C., Magner, T., Lisle, A. T., and Hunter, R. A. (1995). Effects of $\alpha$-adrenoceptor agonists and antagonists on metabolic rate in cattle. Comp. Biochem. Physiol. Part A Physiol. 111, 73-77. doi: 10.1016/0300-9629(95)98522-I

Gefter, A. (2018). "Enactivism," in This Idea is Brilliant, ed J. Brockman (New York, NY: Harper Perennial), 149-151.

Gilbey, M. P. (2007). Sympathetic rhythms and nervous integration. Clin. Exp. Pharmacol. Physiol. 34, 356-361. doi: 10.1111/j.1440-1681.2007.04587.x

Goldstein, D. S. (2003). Catecholamines and stress. Endocr. Regul. 37, 69-80.

Goldstein, D. S. (2019). How does homeostasis happen? integrative physiologic, systems biologic, and evolutionary perspectives. Am. J. Physiol. Regul. Integr. Comp. Physiol. 316, R301-R317. doi: 10.1152/ajpregu.00396.2018

Goldstein, D. S., and Kopin, I. J. (2017). Homeostatic systems, biocybernetics, and autonomic neuroscience. Auton. Neurosci. 208, 15-28. doi: 10.1016/j.autneu.2017.09.001

Grandin, T. (1993). Behavioral agitation during handling of cattle is persistent over time. Appl. Anim. Behav. Sci. 36, 1-9. doi: 10.1016/0168-1591(93)90094-6

Greene, S. A., and Thurmon, J. C. (1988). Xylazine-a review of its pharmacology and use in veterinary medicine. J. Vet. Pharmacol. Ther. 11, 295-313. doi: 10.1111/j.1365-2885.1988.tb00189.x

Guesnet, P., Massoud, M., and Demarne, Y. (1987). Effects of pregnancy and lactation on lipolysis of ewe adipocytes induced by $\beta$-adrenergic stimulation. Mol. Cell. Endocrinol. 50, 177-181. doi: 10.1016/0303-7207(87)90015-3

Habel, J., and Sundrum, A. (2020). Mismatch of glucose allocation between different life functions in the transition period of dairy cows. Animals 10:1028. doi: 10.3390/ani10061028

Hadamitzky, M., Lückemann, L., Pacheco-Lépez, G., and Schedlowski, M. (2020). Pavlovian conditioning of immunological and neuroendocrine functions. Physiol. Rev. 100, 357-405. doi: 10.1152/physrev.00033.2018

Hanna, L. L. H., Garrick, D. J., Gill, C. A., Herring, A. D., Riggs, P. K., Miller, R. K., et al. (2014). Genome-wide association study of temperament and tenderness using different Bayesian approaches in a Nellore-Angus crossbred population. Livest. Sci. 161, 17-27. doi: 10.1016/j.livsci.2013.12.012

Haskell, M. J., Simm, G., and Turner, S. P. (2014). Genetic selection for temperament traits in dairy and beef cattle. Front. Genet. 5:368. doi: $10.3389 /$ fgene. 2014.00368

Hearnshaw, H., Barlow, R., and Want, G. (1979). Development of a "temperament" or handling difficulty score for cattle. Aust. Assoc. Anim. Breed. Genet. 1, 164-166.

Henry, J. P., and Stephens, P. M. (1977). Stress, Health, and the Social Environment: A Sociobiologic Approach To Medicine. New York, NY: Springer Verlag.

Hessing, M. J., Hagelso, A. M., Schouten, W. G., Wiepkema, P. R., and Van Beek, J. A. (1994). Individual behavioral and physiological strategies in pigs. Physiol. Behav. 55, 39-46. doi: 10.1016/0031-9384(94)90007-8

Hine, B. C., Bell, A. M., Niemeyer, D. D. O., Duff, C. J., Butcher, N. M., Dominik, S., et al. (2019). Immune competence traits assessed during the stress of weaning are heritable and favourably genetically correlated with temperament traits in Angus cattle. J. Anim. Sci. 97, 4053-4065. doi: 10.1093/jas/skz260

Hine, B. C., Mallard, B. A., Ingham, A. B., and Colditz, I. G. (2015). "Immune competence in livestock," in Breeding Focus 2014 Improving Resilience, Animal Genetics and Breeding Unit, eds S. Hermesch and S. Dominik (Armidale, NSW: University of New England), 49-64.

Hocquette, J. F., Ortigues-Marty, I., Pethick, D., Herpin, P., and Fernandez, X. (1998). Nutritional and hormonal regulation of energy metabolism in skeletal muscles of meat-producing animals. Livest. Prod. Sci. 56, 115-143. doi: 10.1016/S0301-6226(98)00187-0

Hoemann, K., Khan, Z., Feldman, M., Nielson, C., Devlin, M., Dy, J., et al. (2020). Context-aware experience sampling reveals the scale of variation in affective experience. Sci. Rep. 10:12459. doi: 10.1038/s41598-020-69180-y

Hohtola, E. (2004). "Shivering thermogenesis in birds and mammals," in Life in the cold: evolution, mechanisms, adaptation, and application. Twelfth International Hibernation Symposium, eds B. M. Barnes and H. V. Carey (Fairbanks, AK: Institute of Arctic Biology, University of Alaska), 241-252.
Holmes, J. H. G., Robinson, D. W., and Ashmore, C. R. (1972). Blood lactic acid and behaviour in cattle with hereditary muscular hypertrophy. J. Anim. Sci. 35, 1011-1013. doi: 10.2527/jas1972.3551011x

Holzbauer, M., and Sharman, D. F. (1972). The distribution of catecholamines in vertebrates. Handb. Exp. Pharmacol. 32, 110-185. doi: 10.1007/978-3-642-65249-3_5

Hu, J., Zhou, H., Smyth, A., Luo, Y., and Hickford, J. G. (2010). Polymorphism of the bovine ADRB3 gene. Mol. Biol. Rep. 37, 3389-3392. doi: 10.1007/s11033-009-9927-2

Hulbert, L. E., Carroll, J. A., Burdick, N. C., Randel, R. D., Brown, M. S., and Ballou, M. A. (2011). Innate immune responses of temperamental and calm cattle after transportation. Vet. Immunol. Immunopathol. 143, 66-74. doi: 10.1016/j.vetimm.2011.06.025

Hunter, R. A., Sillence, M. N., Gazzola, C., and Spiers, W. G. (1993). Increasing annual growth rates of cattle by reducing maintenance energy requirements. Aust. J. Agric. Res. 44, 579-595. doi: 10.1071/AR9930579

Husband, A. J. (1993). Role of central nervous system and behaviour in the immune response. Vaccine 11, 805-816. doi: 10.1016/0264-410X(93)90355-2

Irwin, M. R., and Cole, S. W. (2011). Reciprocal regulation of the neural and innate immune systems. Nat. Rev. Immunol. 11, 625-632. doi: 10.1038/nri3042

Iversen, M. W., Bolhuis, J. E., Camerlink, I., Ursinus, W. W., Reimert, I., and Duijvesteijn, N. (2017). Heritability of the backtest response in piglets and its genetic correlations with production traits. Animal 11, 556-563. doi: $10.1017 /$ S1751731116001853

Jensen, P. (2014). Behavior genetics and the domestication of animals. Annu. Rev. Anim. Biosci. 2, 85-104. doi: 10.1146/annurev-animal-022513-114135

Jensen, P., and Toates, F. M. (1997). Stress as a state of motivational systems. Appl. Anim. Behav. Sci. 53, 145-156. doi: 10.1016/S0168-1591(96)01156-2

Johnson, B. J., Smith, S. B., and Chung, K. Y. (2014). Historical overview of the effect of $\beta$-adrenergic agonists on beef cattle production. Asian Aust. J. Anim. Sci. 27:757. doi: 10.5713/ajas.2012.12524

Johnson, J. D., Campisi, J., Sharkey, C. M., Kennedy, S. L., Nickerson, M., Greenwood, B. N., et al. (2005). Catecholamines mediate stress-induced increases in peripheral and central inflammatory cytokines. Neuroscience 135, 1295-1307. doi: 10.1016/j.neuroscience.2005.06.090

Joyner, M. J., and Limberg, J. K. (2014). Blood pressure regulation: every adaptation is an integration? Eur. J. Appl. Physiol. 114, 445-450. doi: 10.1007/s00421-013-2636-5

Kadel, M. J., Johnston, D. J., Burrow, H. M., Graser, H. U., and Ferguson, D. M. (2006). Genetics of flight time and other measures of temperament and their value as selection criteria for improving meat quality traits in tropically adapted breeds of beef cattle. Crop Pasture Sci. 57, 1029-1035. doi: 10.1071/AR05082

Kenney, M. J., and Ganta, C. K. (2011). Autonomic nervous system and immune system interactions. Compr. Physiol. 4, 1177-1200. doi: 10.1002/cphy.c130051

Kilgour, R. J., Melville, G. J., and Greenwood, P. L. (2006). Individual differences in the reaction of beef cattle to situations involving social isolation, close proximity of humans, restraint, and novelty. Appl. Anim. Behav. Sci. 99, 21-40. doi: 10.1016/j.applanim.2005.09.012

King, D. A., Pfeiffer, C. S., Randel, R. D., Welsh Jr., T. H., Oliphint, R. A., Baird, B. E., et al. (2006). Influence of animal temperament and stress responsiveness on the carcass quality and beef tenderness of feedlot cattle. Meat Sci. 74, 546-556. doi: 10.1016/j.meatsci.2006.05.004

Kleckner, I. R., and Quigley, K. S. (2015). "An approach to mapping the neurophysiological state of the body to affective experience," in The Psychological Construction of Emotion, eds L. F. Barrett and J. A. Russell (New York, NY: Guilford Publications), 265-301.

Kleckner, I. R., Zhang, J., Touroutoglou, A., Chanes, L., Xia, C., Simmons, W. K., et al. (2017). Evidence for a large-scale brain system supporting allostasis and interoception in humans. Nat. Hum. Behav. 1:0069. doi: 10.1038/s41562-017-0069

Komolka, K., Albrecht, E., Gotoh, T., and Maak, S. (2017). Abundance of beige and brown adipocyte markers in different adipose depots of cattle at 26 months of age. Adv. Anim. Biosci. 8, s38-s41. doi: 10.1017/S2040470017001662

Koolhaas, J. M. (2008). Coping style and immunity in animals: making sense of individual variation. Brain Behav. Immun. 22, 662-667. doi: 10.1016/j.bbi.2007.11.006 
Koolhaas, J. M., Bartolomucci, A., Buwalda, B., De Boer, S. F., Fluegge, G., Korte, S. M., et al. (2011). Stress revisited: a critical evaluation of the stress concept. Neurosci. Biobehav. Rev. 35, 1291-1301. doi: 10.1016/j.neubiorev.2011.02.003

Koolhaas, J. M., De Boer, S. F., Coppens, C. M., and Buwalda, B. (2010). Neuroendocrinology of coping styles: towards understanding the biology of individual variation. Front. Neuroendocrinol. 31, 307-321. doi: 10.1016/j.yfrne.2010.04.001

Koolhaas, J. M., Korte, S. M., De Boer, S. F., Van Der Vegt, B. J., van Reenen, C. G., Hopster, H., et al. (1999). Coping styles in animals: current status in behavior and stress-physiology. Neurosci. Biobehav. Rev. 23, 925-935. doi: 10.1016/S0149-7634(99)00026-3

Koolhaas, J. M., and van Reenen, C. G. (2016). Interaction between coping style/personality, stress, and welfare: relevance for domestic farm animals. J. Anim. Sci. 94, 2284-2296. doi: 10.2527/jas.2015-0125

Koren, T., Krot, M., Boshnak, N. T., Amer, M., Ben-Shaanan, T., Azulay-Debby, H., et al. (2020). Remembering immunity: neuronal ensembles in the insular cortex encode and retrieve specific immune responses. bioRxiv [Preprint]. doi: $10.1101 / 2020.12 .03 .409813$

Korte, S. M., Koolhaas, J. M., Wingfield, J. C., and McEwen, B. S. (2005). The Darwinian concept of stress: benefits of allostasis and costs of allostatic load and the trade-offs in health and disease. Neurosci. Biobehav. Rev. 29, 3-38. doi: 10.1016/j.neubiorev.2004.08.009

Korte, S. M., Olivier, B., and Koolhaas, J. M. (2007). A new animal welfare concept based on allostasis. Physiol. Behav. 92, 422-428. doi: 10.1016/j.physbeh.2006.10.018

Kotas, M. E., and Medzhitov, R. (2015). Homeostasis, inflammation, and disease susceptibility. Cell 160, 816-827. doi: 10.1016/j.cell.2015.02.010

Kreibig, S. D. (2010). Autonomic nervous system activity in emotion: a review. Biol. Psychol. 84, 394-421. doi: 10.1016/j.biopsycho.2010.03.010

Kremer, L., Holkenborg, S. K., Reimert, I., Bolhuis, J. E., and Webb, L. E. (2020). The nuts and bolts of animal emotion. Neurosci. Biobehav. Rev. 113, 273-286. doi: 10.1016/j.neubiorev.2020.01.028

Kristiansen, T. S., and Fernö, A. (2020). "The predictive brain: perception turned upside down," in The Welfare of Fish, eds T. S. Kristiansen, A. Fernö, M. A. Pavlidis, and H. van de Vis (Cham: Springer), 211-227.

LaBranche, T. P., Ehrich, M. F., and Eyre, P. (2010). Characterization of bovine neutrophil $\beta 2$-adrenergic receptor function. J. Vet. Pharmacol. Ther. 33, 323-331. doi: 10.1111/j.1365-2885.2009.01143.x

Lacetera, N. (2016). "Metabolic stress, heat shock proteins, and innate immune response," in The Innate Immune Response to Noninfectious Stressors, ed M. Amadori (Amsterdam: Elsevier), 107-131.

Lacetera, N., Scalia, D., Franci, O., Bernabucci, U., Ronchi, B., and Nardone, A. (2004). Effects of nonesterified fatty acids on lymphocyte function in dairy heifers. J. Dairy Sci. 87, 1012-1014. doi: 10.3168/jds.S0022-0302(04)73246-4

Lawrence, A. B., Vigors, B., and Sandöe, P. (2019). What is so positive about positive animal welfare? - critical review of the literature. Animals 9:783. doi: 10.3390/ani9100783

Lee, C., Cafe, L. M., Robinson, S. L., Doyle, R. E., Lea, J. M., Small, A. H., et al. (2018). Anxiety influences attention bias but not flight speed and crush score in beef cattle. Appl. Anim. Behav. Sci. 205, 210-215. doi: 10.1016/j.applanim.2017.11.003

Lee, C., Verbeek, E., Doyle, R., and Bateson, M. (2016). Attention bias to threat indicates anxiety differences in sheep. Biol. Lett. 12:20150977. doi: $10.1098 / \mathrm{rsbl} .2015 .0977$

Lees, A. M., Salvin, H. E., Colditz, I. G., and Lee, C. (2020). The influence of temperament on body temperature responses to handling in Angus cattle. Animals 10:172. doi: 10.3390/ani10010172

Lefcourt, A. (1982). Effect of teat stimulation on sympathetic tone in bovine mammary gland. J. Dairy Sci. 65, 2317-2322. doi: 10.3168/jds.S0022-0302(82)82503-4

Liston, A., and Masters, S. L. (2017). Homeostasis-altering molecular processes as mechanisms of inflammasome activation. Nat. Rev. Immunol. 17, 208-214. doi: 10.1038/nri.2016.151

Littlejohn, B. P., Price, D. M., Banta, J. P., Lewis, A. W., Neuendorff, D. A., Carroll, J. A., et al. (2016). Prenatal transportation stress alters temperament and serum cortisol concentrations in suckling Brahman calves. J. Anim. Sci. 94, 602-609. doi: $10.2527 /$ jas.2015-9635
Littlejohn, B. P., Price, D. M., Neuendorff, D. A., Carroll, J. A., Vann, R. C., Riggs, P. K., et al. (2018). Prenatal transportation stress alters genome-wide DNA methylation in suckling Brahman bull calves. J. Anim. Sci. 96, 5075-5099. doi: $10.1093 /$ jas/sky350

Littlejohn, B. P., Price, D. M., Neuendorff, D. A., Carroll, J. A., Vann, R. C., Riggs, P. K., et al. (2020). Influence of prenatal transportation stress-induced differential DNA methylation on the physiological control of behavior and stress response in suckling Brahman bull calves. J. Anim. Sci. 98:skz368. doi: 10.1093/jas/skz368

Llonch, P., Somarriba, M., Duthie, C. A., Haskell, M. J., Rooke, J. A Troy, S., et al. (2016). Association of temperament and acute stress responsiveness with productivity, feed efficiency, and methane emissions in beef cattle: an observational study. Front. Vet. Sci. 3:43. doi: 10.3389/fvets.201 6.00043

Llonch, P., Somarriba, M., Duthie, C. A., Troy, S. M., Roehe, R., Rooke, J. A., et al. (2018). Temperament and dominance relate to feeding behaviour and activity in beef cattle: implications for performance and methane emissions. Animal 12, 2639-2648. doi: 10.1017/S1751731118000617

Lourenco-Jaramillo, D. L., Sifuentes-Rincón, A. M., Parra-Bracamonte, G. M., Rosa-Reyna, X. F., Segura-Cabrera, A., et al. (2012). Genetic diversity of tyrosine hydroxylase (TH) and dopamine b-hydroxylase (DBH) genes in cattle breeds. Genet. Mol. Biol. 35, 435-440. doi: 10.1590/S1415-47572012000300009

Lyons, D. M. (1989). Individual differences in temperament of dairy goats and the inhibition of milk ejection. Appl. Anim. Behav. Sci. 22, 269-282. doi: 10.1016/0168-1591(89)90022-1

Lyons, D. M., Price, E. O., and Moberg, G. P. (1988). Individual differences in temperament of domestic dairy goats: constancy and change. Anim. Behav. 36, 1323-1333. doi: 10.1016/S0003-3472(88)80201-X

MacKay, J. R., and Haskell, M. J. (2015). Consistent individual behavioral variation: the difference between temperament, personality, and behavioral syndromes. Animals 5, 455-478. doi: 10.3390/ani5030366

MacKay, J. R. D., Turner, S. P., Hyslop, J., Deag, J. M., and Haskell, M. J. (2013). Short-term temperament tests in beef cattle relate to long-term measures of behavior recorded in the home pen. J. Anim. Sci. 91, 4917-4924. doi: $10.2527 /$ jas.2012-5473

Mason, W. A. (1984). Animal learning: experience, life modes, and cognitive style. Verh. Deutsch. Zool. Gesellsch. 77, 45-56.

Mason, W. A., and Capitanio, J. P. (2012). Basic emotions: a reconstruction. Emot. Rev. 4, 238-244. doi: 10.1177/1754073912439763

Matt, S. M., and Gaskill, P. J. (2019). Where is dopamine and how do immune cells see it?: dopamine-mediated immune cell function in health and disease. J. Neuroimmune Pharmacol. 15, 1-51. doi: 10.1007/s11481-019-09851-4

Mattiello, S., Battini, M., De Rosa, G., Napolitano, F., and Dwyer, C. (2019). How can we assess positive welfare in ruminants? Animals 9:758. doi: 10.3390/ani9100758

Mazloomi, E., Jazani, N. H., and Shahabi, S. (2012). A novel adjuvant, mixture of alum, and the beta-adrenergic receptor antagonist propranolol, elicits both humoral and cellular immune responses for heat-killed Salmonella typhimurium vaccine. Vaccine 30, 2640-2646. doi: 10.1016/j.vaccine.2012.02.017

McEwen, B. S. (1998). Stress, adaptation, and disease: allostasis and allostatic load. Ann. N. Y. Acad. Sci. 840, 33-44. doi: 10.1111/j.1749-6632.1998.tb09546.x

McEwen, B. S., and Wingfield, J. C. (2003). The concept of allostasis in biology and biomedicine. Horm. Behav. 43, 2-15. doi: 10.1016/S0018-506X(02)00024-7

McEwen, B. S., and Wingfield, J. C. (2010). What's in a name? integrating homeostasis, allostasis, and stress. Horm. Behav. 57, 105-111. doi: 10.1016/j.yhbeh.2009.09.011

McGilchrist, P., Cafe, L. M., Pethick, D. W., Greenwood, P. L., and Gardner, G. E. (2011). "Cattle with more reactive temperaments have lower resting muscle glycogen," in Proceedings 57th International Congress of Meat Science and Technology (Ghent), 1-4.

Mejsnar, J., and Pácha, J. (1983). Thermogenesis due to noradrenaline in muscles under different rates of perfusion. Pflügers Arch. 397, 149-151. doi: 10.1007/BF00582054

Mendl, M., Burman, O. H., Parker, R. M., and Paul, E. S. (2009). Cognitive bias as an indicator of animal emotion and welfare: emerging evidence and underlying mechanisms. Appl. Anim. Behav. Sci. 118, 161-181. doi: 10.1016/j.applanim.2009.02.023 
Mendl, M., Burman, O. H., and Paul, E. S. (2010). An integrative and functional framework for the study of animal emotion and mood. Proc. R. Soc. B Biol. Sci. 277, 2895-2904. doi: 10.1098/rspb.2010.0303

Mendl, M., and Paul, E. S. (2020a). Animal affect and decision-making. Neurosci. Biobehav. Rev. 112, 144-163. doi: 10.1016/j.neubiorev.2020.01.025

Mendl, M., and Paul, E. S. (2020b). "Assessing affective states in animals," in Mental Health and Well-being in Animals, ed F. D. Mcmillan (Wallingford: CABI), 328-344.

Meyer, K., and Colditz, I. G. (2015). "Estimates of genetic parameters for seasonal weight changes of beef cows," in Association for the Advancement of Animal Breeding and Genetics Proceedings (Lorne, VIC), 193-196.

Mignon-Grasteau, S., Boissy, A., Bouix, J., Faure, J. M., Fisher, A. D., Hinch, G. N., et al. (2005). Genetics of adaptation and domestication in livestock. Livest. Prod. Sci. 93, 3-14. doi: 10.1016/j.livprodsci.2004.11.001

Miyashita, T., and Williams, C. L. (2006). Epinephrine administration increases neural impulses propagated along the vagus nerve: role of peripheral $\beta$-adrenergic receptors. Neurobiol. Learn. Memory 85, 116-124. doi: 10.1016/j.nlm.2005.08.013

Moldoff, D. E., and Westneat, D. F. (2017). Foraging sparrows exhibit individual differences but not a syndrome when responding to multiple kinds of novelty. Behav. Ecol. 28, 732-743. doi: 10.1093/beheco/arx014

Monk, J. E., Belson, S., Colditz, I. G., and Lee, C. (2018). Attention bias test differentiates anxiety and depression in sheep. Front. Behav. Neurosci. 12:246. doi: 10.3389/fnbeh.2018.00246

Mormède, P., Andanson, S., Aupérin, B., Beerda, B., Guémené, D., Malmkvist, J., et al. (2007). Exploration of the hypothalamic-pituitary-adrenal function as a tool to evaluate animal welfare. Physiol. Behav. 92, 317-339. doi: 10.1016/j.physbeh.2006.12.003

Mrosovsky, N. (1990). Rheostasis: The Physiology of Change. Oxford: Oxford University Press.

Müller, R., and von Keyserlingk, M. A. (2006). Consistency of flight speed and its correlation to productivity and to personality in Bos taurus beef cattle. Appl. Anim. Behav. Sci. 99, 193-204. doi: 10.1016/j.applanim.2005.05.012

Nakamura, K. (2011). Central circuitries for body temperature regulation and fever. Am. J. Physiol. Regul. Integr. Comp. Physiol. 301, R1207-R1228. doi: 10.1152/ajpregu.00109.2011

Nkrumah, J. D., Crews Jr., D. H., Basarab, J. A., Price, M. A., Okine, E. K., Wang, Z., et al. (2007). Genetic and phenotypic relationships of feeding behavior and temperament with performance, feed efficiency, ultrasound, and carcass merit of beef cattle. J. Anim. Sci. 85, 2382-2390. doi: 10.2527/jas.2006-657

Oliphint, R. A. (2006). Evaluation of the inter-relationships of temperament, stress responsiveness, and immune function in beef calves (Doctoral dissertation). Texas A and M University, College Station, TX, United States.

Oster, M., Scheel, M., Muráni, E., Ponsuksili, S., Zebunke, M., Puppe, B., et al. (2015). The fight-or-flight response is associated with PBMC expression profiles related to immune defence and recovery in swine. PLoS ONE 10:e0120153. doi: 10.1371/journal.pone.0120153

Owen, R. N., Latham, C. M., Long, C. R., Randel, R. D., Welsh Jr., T. H., and White-Springer, S. H. (2020). Temperament influences mitochondrial capacity in skeletal muscle from 8 through 18 mo of age in Brahman heifers. J. Anim. Sci. 98:skaa291. doi: 10.1093/jas/skaa291

Paredes-Sánchez, F. A., Sifuentes-Rincón, A. M., Casas, E., Arellano-Vera, W., Parra-Bracamonte, G. M., Riley, D. G., et al. (2020). Novel genes involved in the genetic architecture of temperament in Brahman cattle. PLOS ONE 15:e0237825. doi: 10.1371/journal.pone.0237825

Parham, J. T., Blevins, S. R., Tanner, A. E., Wahlberg, M. L., Swecker Jr., W. S., and Lewis, R. M. (2021). Subjective methods of quantifying temperament in heifers are indicative of physiological stress. Appl. Anim. Behav. Sci. 234:105197. doi: 10.1016/j.applanim.2020.105197

Pattyn, A., Morin, X., Cremer, H., Goridis, C., and Brunet, J. F. (1999). The homeobox gene Phox $2 \mathrm{~b}$ is essential for the development of autonomic neural crest derivatives. Nature 399, 366-370. doi: 10.1038/20700

Petherick, J. C., Doogan, V. J., Holroyd, R. G., Olsson, P., and Venus, B. K. (2009b). Quality of handling and holding yard environment, and beef cattle temperament: 1. Relationships with flight speed and fear of humans. Appl. Anim. Behav. Sci. 120, 18-27. doi: 10.1016/j.applanim.2009.05.008

Petherick, J. C., Doogan, V. J., Venus, B. K., Holroyd, R. G., and Quinn, P. (2009a). Quality of handling and beef cattle temperament: 2 .
Consequence for stress and productivity. Appl. Anim. Behav. Sci. 120, 28-38. doi: 10.1016/j.applanim.2009.05.009

Pethick, D. W., Harper, G. S., and Dunshea, F. R. (2005). "Fat metabolism and turnover," in Quantitative Aspects of Ruminant Digestion and Metabolism, eds J. Dijkstra and J. M. Forbes (Wallingford: CAB International), 345-371.

Pethick, D. W., Rowe, J. B., and Tudor, G. (1995). Glycogen metabolism and meat quality. Recent Adv. Anim. Nutr. Aust. 7, 97-103.

Prayaga, K. C. (2003). Evaluation of beef cattle genotypes and estimation of direct and maternal genetic effects in a tropical environment. 2. Adaptive and temperament traits. Aust. J. Agric. Res. 54, 1027-1038. doi: 10.1071/AR03071

Prayaga, K. C., and Henshall, J. M. (2005). Adaptability in tropical beef cattle: genetic parameters of growth, adaptive, and temperament traits in a crossbred population. Aust. J. Exp. Agric. 45, 971-983. doi: 10.1071/EA05045

Price, E. O. (1999). Behavioral development in animals undergoing domestication. Appl. Anim. Behav. Sci. 65, 245-271. doi: 10.1016/S0168-1591(99)00087-8

Quigley, K. S., Kanoski, S., Grill, W. M., Barrett, L. F., and Tsakiris, M. (2021). Functions of interoception: from energy regulation to experience of the self. Trends Neurosci. 44, 29-38. doi: 10.1016/j.tins.2020.09.008

Quigley, K. S., and Stifter, C. A. (2006). A comparative validation of sympathetic reactivity in children and adults. Psychophysiology 43, 357-365. doi: 10.1111/j.1469-8986.2006.00405.x

Ramsay, D. S., and Woods, S. C. (2014). Clarifying the roles of homeostasis and allostasis in physiological regulation. Psychol. Rev. 121:225. doi: $10.1037 / \mathrm{a} 0035942$

Rauw, W. M., Johnson, A. K., Gomez-Raya, L., and Dekkers, J. (2017). A hypothesis and review of the relationship between selection for improved production efficiency, coping behavior, and domestication. Front. Genet. 8:134. doi: 10.3389/fgene.2017.00134

Réale, D., Reader, S. M., Sol, D., McDougall, P. T., and Dingemanse, N. J. (2007). Integrating animal temperament within ecology and evolution. Biol. Rev. 82, 291-318. doi: 10.1111/j.1469-185X.2007.00010.x

Reinhardt, C. D., Busby, W. D., and Corah, L. R. (2009). Relationship of various incoming cattle traits with feedlot performance and carcass traits. J. Anim. Sci. 87, 3030-3042. doi: 10.2527/jas.2008-1293

Reiske, L., Schmucker, S., Pfaffinger, B., Weiler, U., Steuber, J., and Stefanski, V. (2020). Intravenous infusion of cortisol, adrenaline, or noradrenaline alters porcine immune cell numbers and promotes innate over adaptive immune functionality. J. Immunol. 204, 3205-3216. doi: 10.4049/jimmunol. 2000269

Romanovsky, A. A. (2018). The thermoregulation system and how it works. Handb. Clin. Neurol. 156, 3-43. doi: 10.1016/B978-0-444-63912-7.00001-1

Russell, J. A., and Barrett, L. F. (1999). Core affect, prototypical emotional episodes, and other things called emotion: dissecting the elephant. J. Pers. Soc. Psychol. 76, 805-819. doi: 10.1037/0022-3514.76.5.805

Sant'Anna, A. C., Paranhos da Costa, M. J. R., Baldi, F., Rueda, P. M., and Albuquerque, L. G.d. (2012). Genetic associations between flight speed and growth traits in Nellore cattle. J. Anim. Sci. 90, 3427-3432. doi: $10.2527 /$ jas.2011-5044

Schuett, W., Dall, S. R., Wilson, A. J., and Royle, N. J. (2013). Environmental transmission of a personality trait: foster parent exploration behaviour predicts offspring exploration behaviour in zebra finches. Biol. Lett. 9:20130120. doi: $10.1098 / \mathrm{rsbl} .2013 .0120$

Schwartzkopf-Genswein, K. S., Shah, M. A., Church, J. S., Haley, D. B., Janzen, K., Truong, G., et al. (2012). A comparison of commonly used and novel electronic techniques for evaluating cattle temperament. Can. J. Anim. Sci. 92, 21-31. doi: 10.4141/cjas2011-040

Sebastian, T., Watts, J., Stookey, J., Buchanan, F., and Waldner, C. (2011). Temperament in beef cattle: methods of measurement and their relationship to production. Can. J. Anim. Sci. 91, 557-565. doi: 10.4141/cjas2010-041

Segerstrom, S. C. (2003). Individual differences, immunity, and cancer: lessons from personality psychology. Brain Behav. Immun. 17, 92-97. doi: 10.1016/S0889-1591(02)00072-7

Sherrington, C. S. (1913). Reflex inhibition as a factor in the co-ordination of movements and postures. Q. J. Exp. Physiol. Trans. Integr. 6, 251-310. doi: 10.1113/expphysiol.1913.sp000142

Sih, A., Bell, A., and Johnson, J. C. (2004). Behavioral syndromes: an ecological and evolutionary overview. Trends Ecol. Evol. 19, 372-378. doi: 10.1016/j.tree.2004.04.009 
Sloan, E. K., Capitanio, J. P., Tarara, R. P., and Cole, S. W. (2008). Social temperament and lymph node innervation. Brain Behav. Immun. 22, 717-726. doi: $10.1016 /$ j.bbi.2007.10.010

Spencer, G. S. G., and Oliver, M. H. (1996). Suppression of immune response in lambs during treatment with the beta-adrenergic agonist clenbuterol. J. Anim. Sci. 74, 151-153. doi: 10.2527/1996.741151x

Stamps, J., and Groothuis, T. G. (2010). The development of animal personality: relevance, concepts, and perspectives. Biol. Rev. 85, 301-325. doi: 10.1111/j.1469-185X.2009.00103.x

Stamps, J. A., and Biro, P. A. (2016). Personality and individual differences in plasticity. Curr. Opin. Behav. Sci. 12, 18-23. doi: 10.1016/j.cobeha.2016.08.008

Stamps, J. A., and Groothuis, T. G. (2010). Developmental perspectives on personality: implications for ecological and evolutionary studies of individual differences. Philos. Trans. R. Soc. B Biol. Sci. 365, 4029-4041. doi: $10.1098 /$ rstb.2010.0218

Sterling, P., and Eyer, J. (1988). “Allostasis: a new paradigm to explain arousal pathology," in Handbook of Life Stress, Cognition, and Health, eds S. Fisher and J. Reason (New York, NY: J. Wiley and Sons), 629-649.

Stewart, M., Webster, J. R., Stafford, K. J., Schaefer, A. L., and Verkerk, G. A. (2010). Effects of an epinephrine infusion on eye temperature and heart rate variability in bull calves. J. Dairy Sci. 93, 5252-5257. doi: 10.3168/jds.2010-3448

Stewart, M., Webster, J. R., Verkerk, G. A., Schaefer, A. L., Colyn, J. J., and Stafford, K. J. (2007). Non-invasive measurement of stress in dairy cows using infrared thermography. Physiol. Behav. 92, 520-525. doi: 10.1016/j.physbeh.2007.04.034

Strandberg, E. (2009). The Role of Environmental Sensitivity and Plasticity in Breeding for Robustness: Lessons From Evolutionary Genetics. BREEDING for Robustness in Cattle. Wageningen: EAAP Publication, 17-33.

Sundlöf, G., and Wallin, B. G. (1977). The variability of muscle nerve sympathetic activity in resting recumbent man. J. Physiol. 272, 383-397. doi: 10.1113/jphysiol.1977.sp012050

Thompson, G. E., and Bell, A. W. (1976). Heat production in the newborn ox during noradrenaline infusion. Neonatology 28, 375-381. doi: 10.1159/000240840

Thorp, A. A., and Schlaich, M. P. (2015). Relevance of sympathetic nervous system activation in obesity and metabolic syndrome. J. Diabetes Res. 2015:341583. doi: $10.1155 / 2015 / 341583$

Trut, L., Oskina, I., and Kharlamova, A. (2009). Animal evolution during domestication: the domesticated fox as a model. Bioessays 31, 349-360. doi: 10.1002/bies.200800070

Tulloh, N. M. (1961). Behaviour of cattle in yards. II. A study of temperament. Anim. Behav. 9, 25-30. doi: 10.1016/0003-3472(61)90046-X

Valente, T. S., Baldi, F., Sant'Anna, A. C., Albuquerque, L. G., and Paranhos da Costa, M. J. R. (2016). Genome-Wide Association Study between single nucleotide polymorphisms and flight speed in Nellore cattle. PLoS ONE 11:e0156956. doi: 10.1371/journal.pone.0156956

van Reenen, C. G., Engel, B., Ruis-Heutinck, L. F. M., Van der Werf, J. T. N., Buist, W. G., Jones, R. B., et al. (2004). Behavioural reactivity of heifer calves in potentially alarming test situations: a multivariate and correlational analysis. Appl. Anim. Behav. Sci. 85, 11-30. doi: 10.1016/j.applanim.2003.09.007

Van Reenen, C. G., O'Connell, N. E., Van der Werf, J. T. N., Korte, S. M., Hopster, H., Jones, R. B., et al. (2005). Responses of calves to acute stress: Individual consistency and relations between behavioral and physiological measures. Physiol. Behav. 85, 557-570. doi: 10.1016/j.physbeh.2005.06.015

van Reenen, C. G., Van der Werf, J. T. N., Bruckmaier, R. M., Hopster, H., Engel, B., Noordhuizen, J. P. T. M., et al. (2002). Individual differences in behavioral and physiological responsiveness of primiparous dairy cows to machine milking. J. Dairy Sci. 85, 2551-2561. doi: 10.3168/jds.S0022-0302(02)74338-5

Velie, B. D., Maltecca, C., and Cassady, J. P. (2009). Genetic relationships among pig behavior, growth, backfat, and loin muscle area. J. Anim. Sci. 87, 2767-2773. doi: $10.2527 /$ jas.2008-1328

Vicente, S., Gonzalez, M. P., and Oset-Gasque, M. J. (2002). Neuronal nitric oxide synthase modulates basal catecholamine secretion in bovine chromaffin cells. $J$. Neurosci. Res. 69, 327-340. doi: 10.1002/jnr.10222
Voisinet, B. D., Grandin, T., O'Connor, S. F., Tatum, J. D., and Deesing, M. J. (1997a). Bos indicus cross feedlot cattle with excitable temperaments have tougher meat and a higher incidence of borderline dark cutters. Meat Sci. 46, 367-377. doi: 10.1016/S0309-1740(97)00031-4

Voisinet, B. D., Grandin, T., Tatum, J. D., OConnor, S. F., and Struthers, J. J. (1997b). Feedlot cattle with calm temperaments have higher average daily gains than cattle with excitable temperaments. J. Anim. Sci. 75, 892-896. doi: $10.2527 / 1997.754892 \mathrm{x}$

von Borell, E., Langbein, J., Després, G., Hansen, S., Leterrier, C., Marchant-Forde, J., et al. (2007). Heart rate variability as a measure of autonomic regulation of cardiac activity for assessing stress and welfare in farm animals-a review. Physiol. Behav. 92, 293-316. doi: 10.1016/j.physbeh.2007.01.007

Waddington, C. H. (1957). The Strategy of the Genes. London: Routledge.

Wallin, B. G., Sundlöf, G., Ericksson, B., Dominiak, P., Grobecker, H., and Lindblad, L. E. (1981). Plasma noradrenaline correlates to sympathetic muscle nerve activity in normotensive man. Acta Physiol. Scand. 111, 69-73. doi: 10.1111/j.1748-1716.1981.tb06706.x

Webb, L. E., Veenhoven, R. R., Harfeld, J. L. J., and Jensen, M. B. (2018). What is animal happiness? Ann. N. Y. Acad. Sci. 1438, 62-76. doi: 10.1111/nyas.13983

Wellman, P. J. (2005). Modulation of eating by central catecholamine systems. Curr. Drug Targets 6, 191-199. doi: 10.2174/1389450053174532

Wilkins, A. S. (2020). A striking example of developmental bias in an evolutionary process: the "domestication syndrome." Evol. Dev. 22, 143-153. doi: 10.1111/ede.12319

Wilkins, A. S., Wrangham, R. W., and Fitch, W. T. (2014). The "domestication syndrome" in mammals: a unified explanation based on neural crest cell behavior and genetics. Genetics 197, 795-808. doi: 10.1534/genetics.114.165423

Williams, A. F., Boles, J. A., Herrygers, M. R., Berardinelli, J. G., Meyers, M. C., and Thomson, J. M. (2019). Blood lactate and rectal temperature can predict exit velocity of beef feedlot steers. Trans. Anim. Sci. 3, 1530-1542. doi: 10.1093/tas/txz135

Williams, P. E. V., Pagliani, L., Innes, G. M., Pennie, K., Harris, C. I., and Garthwaite, P. (1987). Effects of a ß-agonist (clenbuterol) on growth, carcass composition, protein, and energy metabolism of veal calves. Br. J. Nutr. 57, 417-428. doi: 10.1079/BJN19870049

Wirtshafter, D., and Davis, J. D. (1977). Set points, settling points, and the control of body weight. Physiol. Behav. 19, 75-78. doi: 10.1016/0031-9384(77)90162-7

Wohleb, E. S. (2019). “Autonomic control of immune function," in Oxford Research Encyclopedia of Neuroscience, ed S. M. Sherman (New York, NY: Oxford University Press) 1-25. doi: 10.1093/acrefore/9780190264086.013.275

Wood, S. H., Hindle, M. H., Mizoro, Y., Cheng, Y., Saer, B. R., Miedzinska, K., et al. (2020). Circadian clock mechanism driving mammalian photoperiodism. Nat. Commun. 11:4291. doi: 10.1038/s41467-020-18061-z

Ye, J., and Medzhitov, R. (2019). Control strategies in systemic metabolism. Nat. Metab. 1, 947-957. doi: 10.1038/s42255-019-0118-8

Zebunke, M., Repsilber, D., Nuernberg, G., Wittenburg, D., and Puppe, B. (2015). The backtest in pigs revisited-an analysis of intra-situational behaviour. Appl. Anim. Behav. Sci. 169, 17-25. doi: 10.1016/j.applanim.2015. 05.002

Zuckerman, M. (1995). Good and bad humors: biochemical bases of personality and its disorders. Psychol. Sci. 6, 325-332. doi: 10.1111/j.1467-9280.1995.tb00521.x

Conflict of Interest: The author declares that the research was conducted in the absence of any commercial or financial relationships that could be constructed as a potential conflict of interest.

Copyright (c) 2021 Colditz. This is an open-access article distributed under the terms of the Creative Commons Attribution License (CC BY). The use, distribution or reproduction in other forums is permitted, provided the original author(s) and the copyright owner(s) are credited and that the original publication in this journal is cited, in accordance with accepted academic practice. No use, distribution or reproduction is permitted which does not comply with these terms. 